\title{
Development and validation of the prognostic value of the immune-related genes in clear cell renal cell carcinoma
}

\author{
Zhuangyao Liao, Haohua Yao, Jinhuan Wei, Zihao Feng, Wei Chen, Junhang Luo, Xu Chen \\ Department of Urology, The First Affiliated Hospital of Sun Yat-Sen University, Guangzhou, China \\ Contributions: (I) Conception and design: Z Liao; (II) Administrative support: X Chen, W Chen, J Luo; (III) Provision of study materials: H Yao; \\ (IV) Collection and assembly of data: J Wei; (V) Data analysis: Z Liao, Z Feng; (VI) Manuscript writing: Z Liao, X Chen; (VII) Final approval of \\ manuscript: All authors. \\ Correspondence to: Xu Chen. Department of Urology, The First Affiliated Hospital, Sun Yat-Sen University, Guangzhou 510080, China. \\ Email: chenxu25@mail.sysu.edu.cn.
}

Background: Clear cell renal cell carcinoma (ccRCC) is a highly heterogeneous tumor, resulting a challenge of developing target therapeutics. Not long ago, immune checkpoint blockade regimens combine with tyrosin kinase inhibitors have evolved frontline options in metastatic RCC, which implies arrival of the era of tumor immunotherapy. Studies have demonstrated immune-related genes (IRGs) could characterize tumor milieu and related to patient survival. Nevertheless, the clinical significance of classifier depending on IRGs in ccRCC has not been well established.

Methods: The R package limma, univariate and LASSO cox regression analysis were used to screen the prognostic related IRGs from TCGA database. Multivariate cox regression was utilized to establish a risk prediction model for candidate genes. Quantitative real-time PCR was used to confirm the expression of candidates in clinical samples from our institution. CIBERSORT algorithm and correlation analysis were applied to explore tumor-infiltrating immune cells signature between different risk groups. A clinical nomogram was also developed to predict OS by using the rms $\mathrm{R}$ package based on the risk prediction model and other independent risk factors. The ICGC data was used for external validation of either gene risk model or nomogram.

Results: We identified 382 differentially expressed immune related genes. Four unique prognostic IRGs (CRABP2, LTB4R, PTGER1 and TEK) were finally affirmed to associate with tumor survival independently and utilized to establish the risk score model. All candidates' expression was successfully laboratory confirmed by q-PCR. CIBERSORT analysis implied patients in unfavorable-risk group with high CD8 T cell, regulatory T cell and NK cell infiltration, as well as high expression of PD-1, CTLA4, TNFRSF9, TIGIT and LAG3. A nomogram combined IRGs risk score with age, gender, TNM stage, Fuhrman grade, necrosis was further generated to predict of 3- and 5-year OS, which exhibited superior discriminative power (AUCs were 0.811 and 0.795).

Conclusions: Our study established and validated a survival prognostic model system based on 4 unique immune related genes in ccRCC, which expands knowledge in tumor immune status and provide a potent prediction tool in future.

Keywords: Clear cell renal cell carcinoma (ccRCC); immunity; prognosis signature; tumor biomarkers; tumor microenvironment

Submitted Oct 18, 2020. Accepted for publication Feb 10, 2021.

doi: $10.21037 /$ tau-20-1348

View this article at: http://dx.doi.org/10.21037/tau-20-1348 


\section{Introduction}

Clear cell renal cell carcinoma (ccRCC) representing approximately $75 \%$ of RCC cases with more than 175000 deaths per year (1). Although surgical resection is effective for localized RCC, about one-third cases suffered recurrences and metastases with worse prognosis (2). Various molecular signatures of ccRCC implies that distinct survival advantages exist in the certain subtypes $(3,4)$. Owing to heterogeneity, discovering reliable molecular biomarkers can help to improve prognostic determination and guide clinical decision. Actually, RCC is believed to be an immunogenic tumor for long time. Interleukin 2 (IL-2) and interferon alpha (IFN-a) were used for therapeutic regimens for advanced RCC in the 1990s to early 2000s, and the incidence of complete remission was about 3-5\% $(5,6)$. Recently, trail of KEYNOTE-426 and JAVELIN Renal 101 demonstrates using PD-1 immune checkpoint inhibitor-based combination regimens as the first line setting can significantly improve advanced RCC survival, which have been approved by $\operatorname{FDA}(7,8)$. Therefore, further exploration of immune related molecular network in RCC definitely helps to develop comprehensive understanding of immune evasion and provide insights into making therapeutic strategy. Immune molecular regulation is the key mechanism for host innate immunity and immune surveillance. It is necessary to explore clinical significance of immune-related biomarkers, especially immune-related genes (IRGs) which could predict prognosis of patients, and potentially portrait tumor microenvironment (TME) $(9,10)$.

In this study, we identified 4 immune-related genes (CRABP2, LTB4R, PTGER1 and TEK) through integrated analyses of mRNA expression data from TCGA database and independently assessed. Multivariate Cox proportional hazards models were constructed by 4 genes and validated the accuracy in an external ICGC dataset. Moreover, we investigated a high proportion of CD8 $\mathrm{T}$ cell, regulatory $\mathrm{T}$ cell and NK cell in the unfavorable-risk group. High levels of immune response suppressors (PD-1, CTLA4, TNFRSF9, TIGIT and LAG3) were observed in unfavorable-risk group and positively correlated with risk score. According to aforementioned data, a nomogram was well established for clinical use and also externally validated its superior power by ICGC data.

We present the following article in accordance with the TRIPOD reporting checklist (available at http://dx.doi. org/10.21037/tau-20-1348).

\section{Methods}

\section{Study design and dataset information}

The work flow of our study is shown in Figure 1. The expression profile and clinical data of $539 \mathrm{ccRCC}$ patients in TCGA-KIRC dataset were downloaded from TCGA portal (online URL: https://cdn.amegroups.cn/static/public/tau20-1348-1.pdf) and 91 RCC patients from ICGC database were downloaded from ICGC portal (online URL: https:// dcc.icgc.org/). Immune-related genes list was downloaded from the ImmPort database (online URL: https://www. immport.org/home/). All data were preprocessed in $\mathrm{R}$ software (online URL: https://www.r-project.org/; version 3.6.0;). 518 patients in TCGA-KIRC cohort and 91 patients in ICGC cohort with clinical information (Table S1 and S2) were screened for subsequent analyses. All procedures performed in this study were in accordance with the Declaration of Helsinki (as revised in 2013).

\section{Identification of IRDEGs in TCGA-KIRC dataset}

Differential analysis was conducted in TCGA-KIRC dataset through limma package $(11,12)$, with the following cutoff: adjusted $\mathrm{P}$ value $<0.05$ and absolute $\log _{2} \mathrm{FC}>1.5$. The differentially expressed genes list and immune-related genes list from the ImmPort database were uploaded into the Venn diagram online software (online URL: http:// bioinformatics.psb.ugent.be/webtools/Venn/) to obtain the IRDEGs. The heatmap of IRDEGs expression was performed by pheatmap package.

\section{Construction and validation of the risk model}

518 patients in TCGA-KIRC dataset were included as a training set while 91 patients in the ICGC database were assigned as a validation set. Univariate Cox proportional hazards regression analysis was applied to identify the significant prognostic factors associated with OS, and Lasso regression was used to exclude overfitting genes. The candidate genes were analyzed in a multivariate Cox proportional hazards regression analysis to estimate their relative contributions to survival prediction. Subsequently, a prognostic model was constructed: risk score $=$ expression of gene ${ }_{1} \times \beta 1+$ expression of gene ${ }_{2} \times \beta 2+\ldots \ldots+$ expression of gene $e_{n} \times \beta n(13,14)$. According to the median risk score, patients were divided into two groups (favorable-risk 


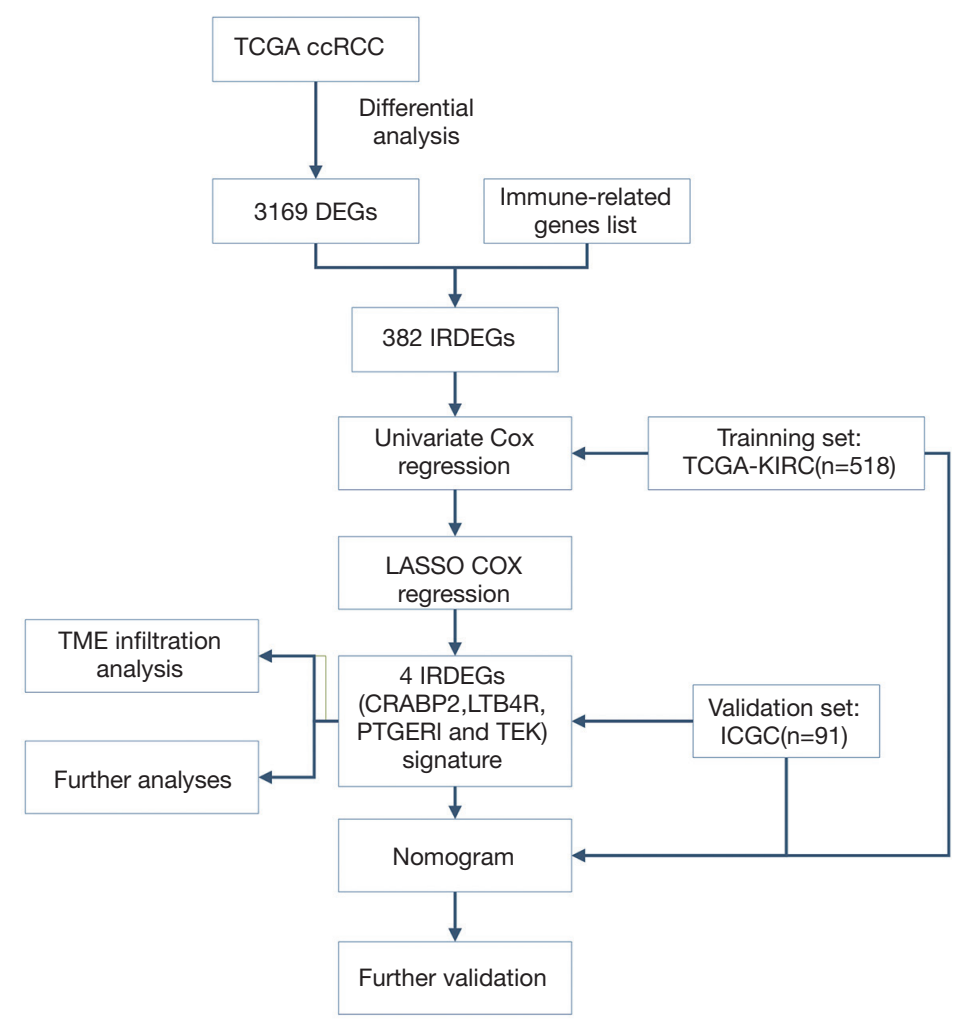

Figure 1 The workflow of our research project. Differential analysis was conducted in TCGA-KIRC dataset to obtain differentially expressed with the following cut-off: adjusted $\mathrm{P}$ value $<0.05$ and absolute $\log 2 \mathrm{FC}>1.5 ; 382$ immune-related genes were identified after taking intersection of the lists of DEGs and IRGs; 4 IRDEGs (CRABP2, LTB4R, PTGER1 and TEK) were finally identified and used to constructed a prognostic model after univariate cox and LASSO cox analyses. Further analyses were conducted to validate the robustness of model and explored the potential mechanism.

group and unfavorable-risk group), and we applied the Kaplan-Meier and log-rank methods to test whether the survival distribution of different groups was equal. Receiver operating characteristic (ROC) curves were used to assess the predictive value of the risk model according to the areas under the respective ROC curves (AUCs). Time-dependent ROC curve analysis was conducted by using the survival ROC package (15).

\section{RNA extraction and qRT-PCR analysis}

Total RNA of 35 pairs of ccRCC and normal tissues RNA were extracted using a Trizol reagent, and $500 \mathrm{ng}$ of RNA was used to synthesize cDNA, and qRT-PCR was performed on ABI system. The primer sequences are listed in Table S3.

\section{Estimation of TME infiltration between groups}

CIBERSORT, a deconvolution algorithm to characterize different cell compositions of the samples based on the immune gene signature sets, including 547 genes and 22 immune cell subtypes (16). We downloaded the result of 518 patients in TCGA cohort calculated by CIBERSORT algorithm from TIMER 2.0(Online URL: http://timer. cistrome.org/) (17) to estimate the infiltration of 22 different immune cell subtypes in the TME for further investigation of the composition and difference between favorable-risk and unfavorable-risk group. Each sample had been calculated a proportion in each cell subtype to estimate the relative abundance of TME immune infiltrating cells. Wilcox test was applied to compare the infiltration proportion of the 22 cell types between the unfavorable-risk group and the favorable-risk group. 


\section{Construction and validation of the clinical nomogram}

We constructed a nomogram, which was widely used to predict the survival probability of patients in clinical (18), with the incorporation of age, gender, TNM stage, Fuhrman grade, necrosis and risk score through $\mathrm{R}$ rms package. We also used ROC curves to evaluate the predictive performance of nomogram at 1-, 3- and 5-year. In addition, calibration curves were used to evaluate the accuracy of the predicted survival time for 3- and 5-year OS, and decision curve analysis (DCA) was performed to evaluate the clinical application benefit between different variables.

\section{Statistical analysis}

All statistical analyses were performed by $\mathrm{R}$ software with the cut-off of $\mathrm{P}<0.05$. Univariate and multivariate Cox proportional hazards regression analyses were used for identifying of prognosis-related IRDEGs and independent prognostic factors. Spearman correlation test was applied to analyze the correlation between the risk score and the expression of immune checkpoint genes. Survival data were calculated using the Kaplan-Meier method and the logrank test. The relative expression level of four IRDEGs was analyzed by paired $t$ test.

\section{Results}

\section{Identification of IRDEGs in ccRCC}

After differential analysis in TCGA-KIRC cohort, 3,169 DEGs were detected (adjusted $\mathrm{P}$ value $<0.05$ and absolute $\log _{2} \mathrm{FC}$ $>1.5$ ), among which 1,635 genes were upregulated, and 1534 genes were downregulated (Figure 2A). Taking the intersection of DEGs and the immune-related genes list, 382 IRDEGs were identified (Figure 2B), with 253 IRDEGs upregulated and 129 IRDEGs downregulated. The heatmap to visualize the expression of 382 IRDEGs in normal samples and tumor samples is shown in Figure $2 C$, and the result of differential analysis are shown in https://cdn.amegroups.cn/ static/public/tau-20-1348-2.xlsx and Table S4.

\section{Construction of prognostic model in TCGA cobort}

175 IRDEGs was calculated to be significantly associated with OS after univariate Cox regression analysis $(\mathrm{P}<0.05)$ (Table S5). Lasso regression was used to filter genes to obtain 8 candidate genes (Figure 2D,2E), which were subsequently included in the multivariate Cox regression analysis. A prognostic gene signature consisting of 4 genes was ultimately constructed with the $\mathrm{P}$ value $<0.05$ in multivariate Cox regression analysis (Table 1 and Table S6). Among these 4 genes, TEK was identified as a protective gene because of its hazard ratios $(\mathrm{HR})$ value of $<1$, while CRABP2, LTB4R and PTGER1 were considered to be predictive genes of poor prognosis. Based on the analysis result, we constructed a computational formula: risk score $=(0.074 \times$ expression level of $C R A B P 2)+(0.165 \times$ expression level of $L T B 4 R)+(0.052 \times$ expression level of PTGER1) $+(-0.203 \times$ expression level of TEK), and the expression level was obtained by the $\log 2$-transformed FPKM+1 of each gene. Subsequently, a total of 518 patients in TCGA cohort were divided into two groups (unfavorable-risk group and favorable-risk group) according to the median risk score. Figure $3 A$ shows the distribution of risk scores, patient survival status and the four gene expression levels in the 518 patients, which were sorted by the risk score of the four-gene signature. As the risk score increasing, the expression of the 4 IRDEGs also changed accordingly, and the prognosis of patients also became worse. Besides, as Figure $3 B$ and $3 C$ show, there were obvious differences in both OS and PFS between the two groups $(\mathrm{P}<0.0001)$. On the other hand, a time-dependent ROC was used to assess the prognostic value of the four-gene signature in the training set. The AUCs of the signature were respectively $0.744,0.734$, and 0.753 for the 1-, 3- and 5-year OS (Figure 3D) while for the 1-, 3- and 5-year PFS were 0.696, 0.711 , and 0.734 (Figure $3 E$ ), indicating our risk model had a good performance on predicting prognosis. Besides, further analysis showed risk score was an independent prognostic factor (HR: 3.137; 95\% CI: 2.383-4.131; $\mathrm{P}<0.001$ ) (Table 1).

\section{External validation of prognostic model in ICGC cohort}

We used the data from ICGC database as an external validation (Figure 4). The distribution of risk scores and survival status of patients, as well as the expression level of the 4 IRDEGs in ICGC cohort, were shown in Figure $4 A$ and it was observed that the expression had an obvious difference between unfavorable-risk group and favorable-risk group. Besides, Kaplan-Meier analysis indicated that unfavorable-risk group was significantly associated with a poor prognosis $(\mathrm{P}<0.05)$, consistently with the above results (Figure $4 B$ ). And the AUCs of ROC analysis were respectively $0.635,0.638$ and 0.635 at $1-, 3-$ and 5 -year OS value, indicating the stability of risk model in different cohorts (Figure 4C). 

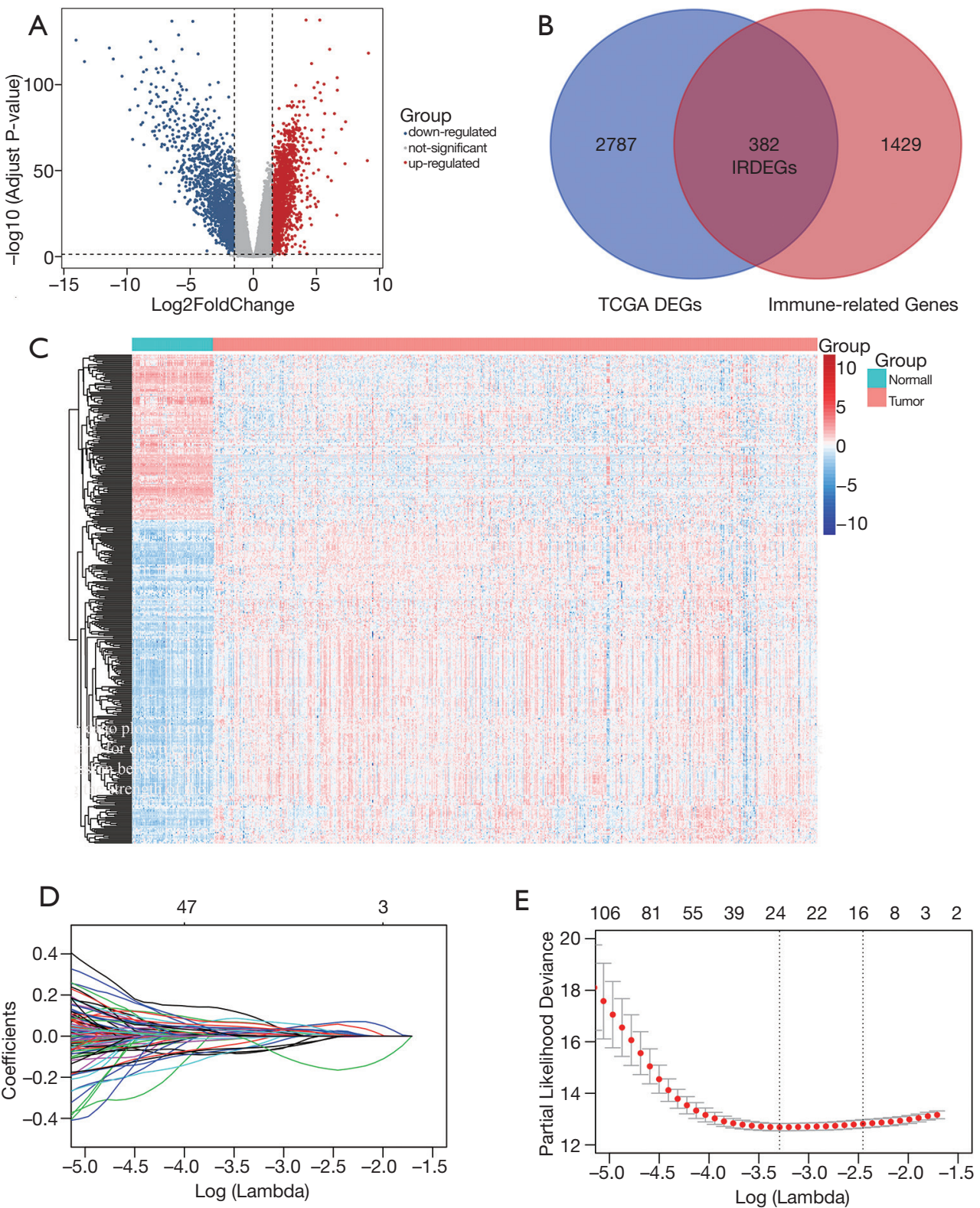

Figure 2 Differential analysis of TCGA-KIRC cohort and LASSO regression. (A) The volcano plot of TCGA-KIRC cohort. Red plots represent upregulated genes while blue plots represent downregulated genes both with adj.P $<0.05$. (B) Venn diagram of DEGs and IRGs. (C) The heatmap of 382 IRDEGs in ccRCC and normal samples. Each column represents one sample and each row represents one gene. The gradual color ranging from blue to red represents the changing process from down to up regulation. (D) Plot of LASSO coefficient profiles. (E) Plot of partial likelihood deviance for the 382 IRDEGs. 
Table 1 Univariate analysis and Multivariate analysis of the 4 IRGs and signature

\begin{tabular}{|c|c|c|c|c|c|}
\hline & \multicolumn{2}{|c|}{ Univariate analysis } & \multicolumn{3}{|c|}{ Multivariate analysis } \\
\hline \multicolumn{6}{|l|}{ Gene symbol } \\
\hline CRABP2 & $1.077(1.001-1.158)$ & 0.0508 & 0.672 & 0.0210 & -0.3979 \\
\hline LTB4R & $1.180(1.001-1.390)$ & 0.0029 & 1.217 & 0.0300 & 0.1961 \\
\hline TEK & $0.639(0.711-0.936)$ & $P<0.001$ & 0.754 & 0.0150 & -0.2817 \\
\hline \multicolumn{6}{|l|}{ Factors } \\
\hline Age & $1.030(1.016-1.043)$ & $P<0.001$ & $1.031(1.016-1.045)$ & $P<0.001$ & \\
\hline Stage & & $P<0.001$ & & & \\
\hline III & 2.656 (1.755-4.019 & & 1.937 (1.272-2.952) & 0.002 & \\
\hline IV & 6.685 (4.537-9.851) & & $5.239(3.524-7.787)$ & $P<0.001$ & \\
\hline Four-gene signature & & & $3.137(2.383-4.131)$ & $P<0.001$ & \\
\hline
\end{tabular}
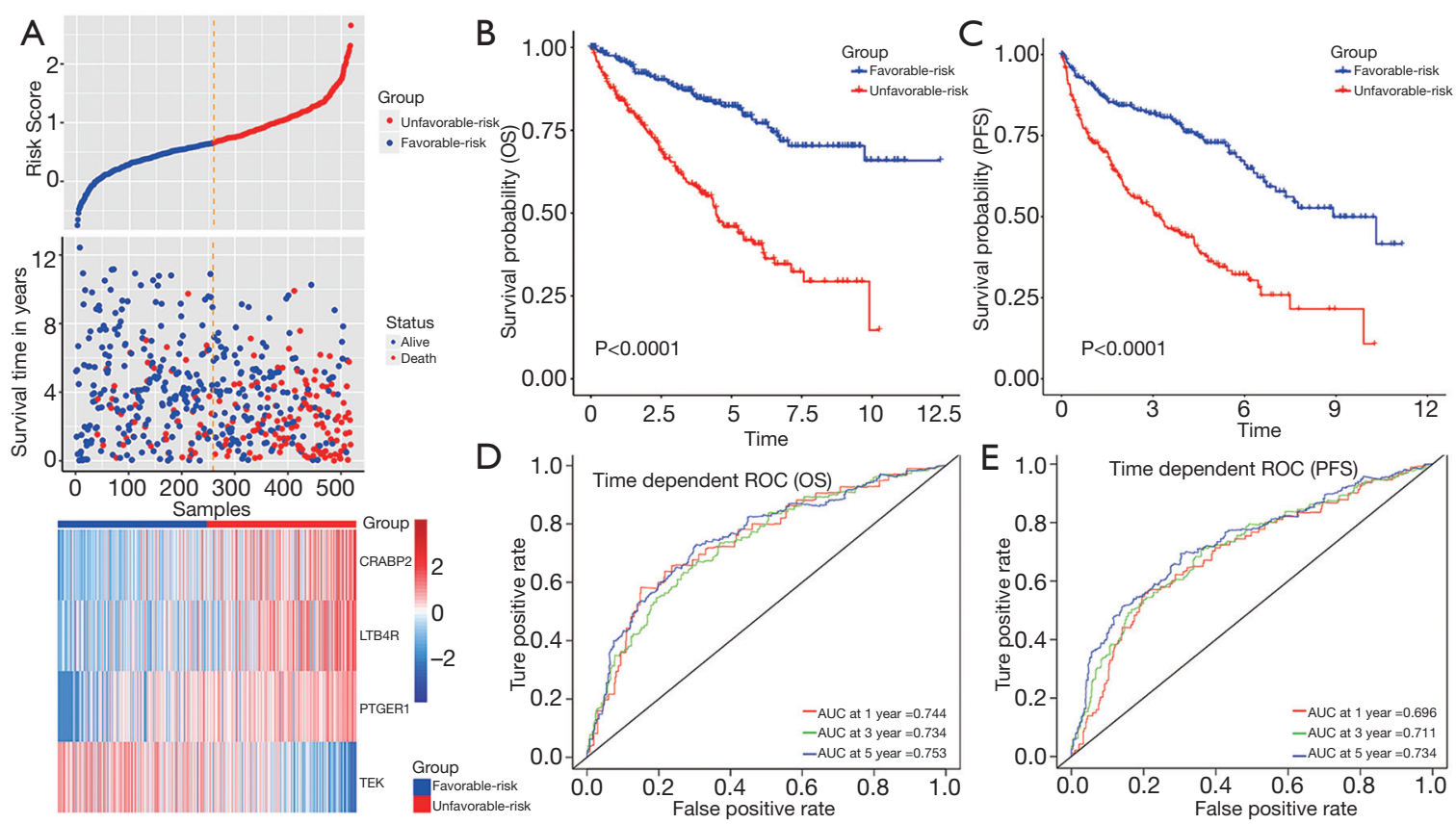

Figure 3 The 4-IRG prognostic signature in the ccRCC patients (TCGA cohort). (A) From top to bottom are the risk score distribution, the patients' survival status distribution, and the heatmap of the 4 genes for low and unfavorable-risk groups, in which each column represents one sample and each row represents one gene. (B, C) The Kaplan-Meier curves of OS and PFS for low and unfavorable-risk groups. (D, E) The ROC curves for predicting OS and PFS in training set by the risk score and the AUC of 1, 3, 5-year. 

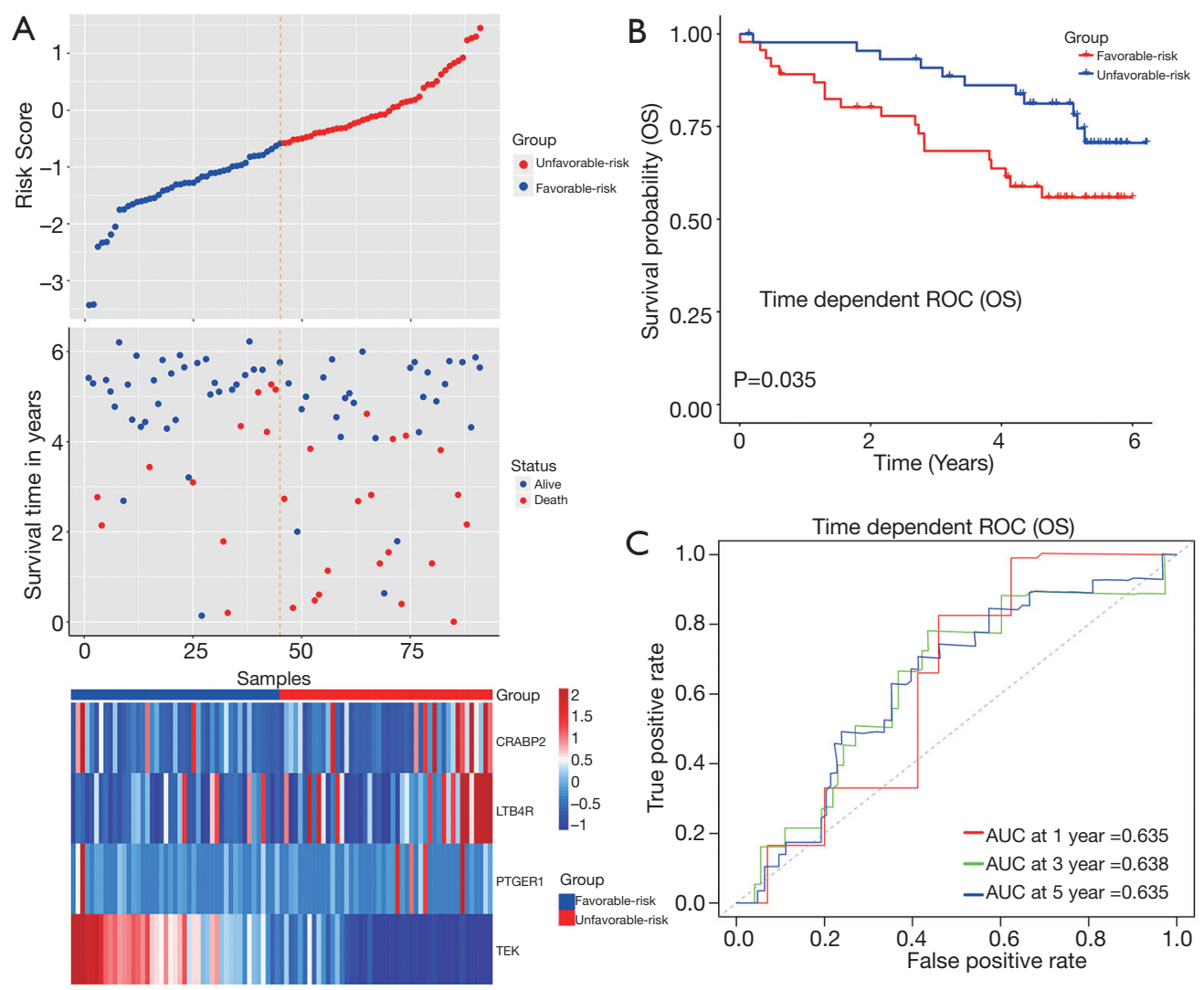

Figure 4 The 4-IRG prognostic signature in the ICGC cohort. (A) From top to bottom are the risk score distribution, the patients' survival status distribution, and the heatmap of the 4 genes for low and unfavorable-risk groups (B) The Kaplan-Meier curves for low and unfavorable-risk groups. (C) The ROC curves for predicting OS in validation set by the risk score and the AUC of 1, 3, 5-year.

\section{Validation in clinical samples}

We used 35 pairs of ccRCC (Table S7) and normal tissues to detect the expression of the four IRDEGs. The results showed LTB4R was high expressed in ccRCC compared with normal tissues, and CRABP2, PTGER1, TEK were low expressed, consistent with the expression data of TCGA database (Figure 5).

\section{TME immune cell infiltration analysis and immune checkpoints analysis}

We summarized the result of 518 ccRCC patients calculated by CIBERSORT algorithm (Figure S1) and compared all the immune cell subtypes in two groups (Table S8). Infiltration proportion of partial cell subtypes have an obvious difference between two groups, among which mainly CD8 $\mathrm{T}$ cell, follicular helper $\mathrm{T}$ cell, regulatory $\mathrm{T}$ cell, activated NK cell, M0 Macrophage have a higher infiltration proportion in the unfavorable-risk group, while M1 Macrophage, M2 Macrophage and other cell types have a lower proportion (Figure 6A). We further explored the expression of the $\mathrm{T}$ cell exhaustion-related markers and immunomodulators (PD-1, CTLA4, TNFRSF9, TIGIT, LAG3) in two groups and found all markers in the unfavorable-risk group were upregulated, indicating an immunosuppressive and exhausted phenotype in the unfavorable-risk group (Figure 6B). Subsequent correlation analysis also showed a positive correlation between risk score and the above markers (Figure $6 C$ ). Based on the above analyses, we found two groups had a significant distinct pattern of immune infiltration, which may lead to different survival benefits.

\section{Construction and validation of the nomogram}

We constructed a nomogram containing age, gender, TNM stage, Fuhrman grade, necrosis and risk score to 

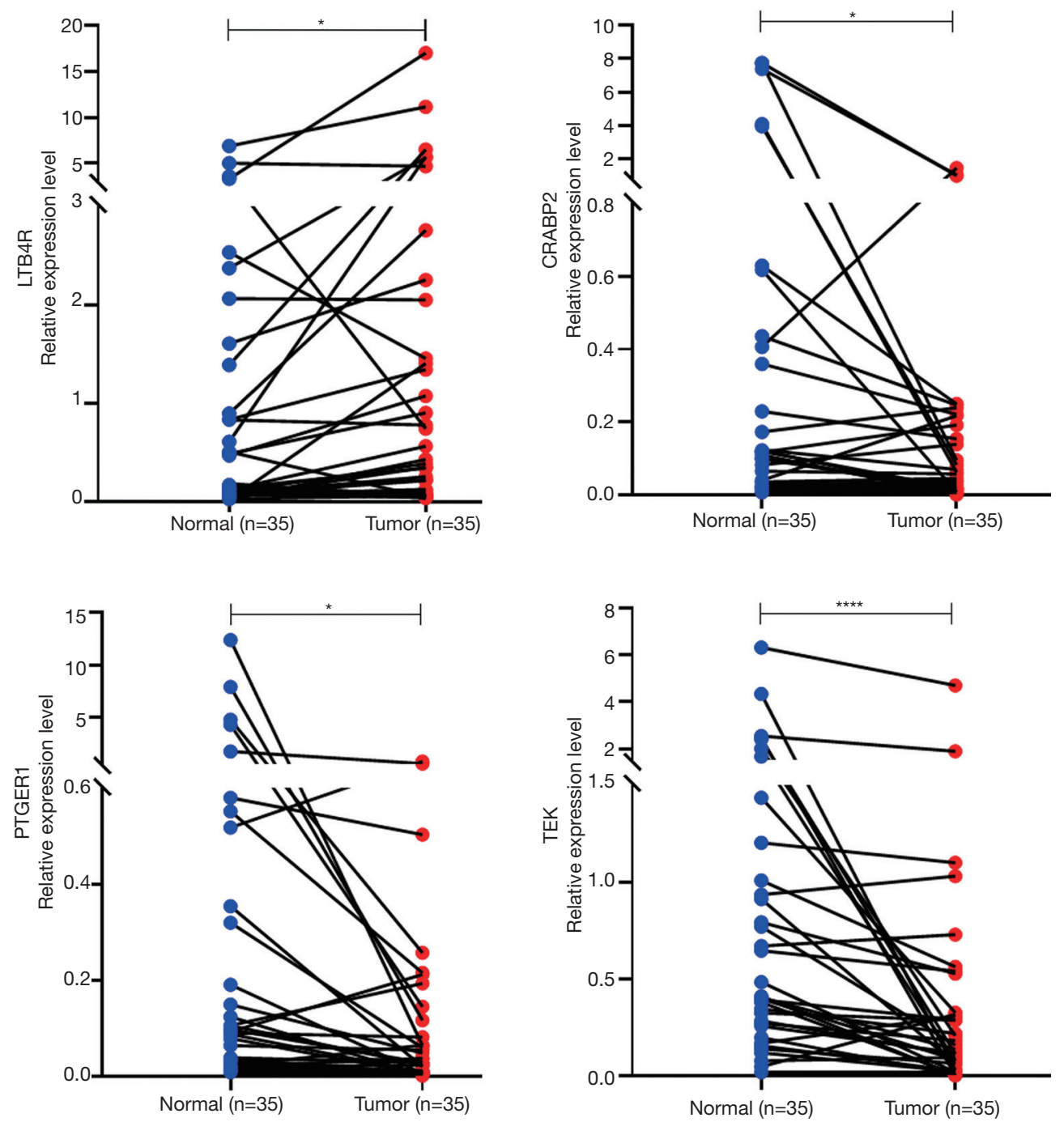

Figure 5 Relative expression level of the 4 IRGs in paired ccRCC and normal tissues.

predict 3- and 5-year survival probability. Each variable had a corresponding score (Table S9), and an overall score could be finally calculated to predict the survival probability at the corresponding time (Figure $7 A$ ). To validate the performance of nomogram, we conducted the ROC analysis, and the result showed respective AUCs were 0.811 and 0.795 in the TCGA cohort (Figure 7B). The calibration curves showed good consistency between the actual and predicted outcomes of 3- and 5-year OS (Figure 7C). Decision curve analysis (DCA) was also conducted, and all variable curves were above the two solid curves. The curve of the nomogram was above the curve of risk score at 3and 5 -year (Figure $7 D$ ), indicating nomogram had a better clinical net benefit. We also constructed another nomogram containing age, gender, TNM stage, and risk score. And the AUCs were $0.811,0.786$ while in the validation set were $0.728,0.713$ at 3 -, 5 -year, suggesting its stability and effectiveness (Figures S2, S3). Calibration curves and DCA also showed the robustness of our nomogram.

\section{Discussion}

Immune related genes (IRGs) play an important role in tumor immune infiltration as well as tumor progression in ccRCC $(19,20)$ and strongly influence complicate soluble factors secretion, which correlate with therapeutic response and clinical outcome (21). IRGs based prognostic model have been successfully developed for hepatocellular, 

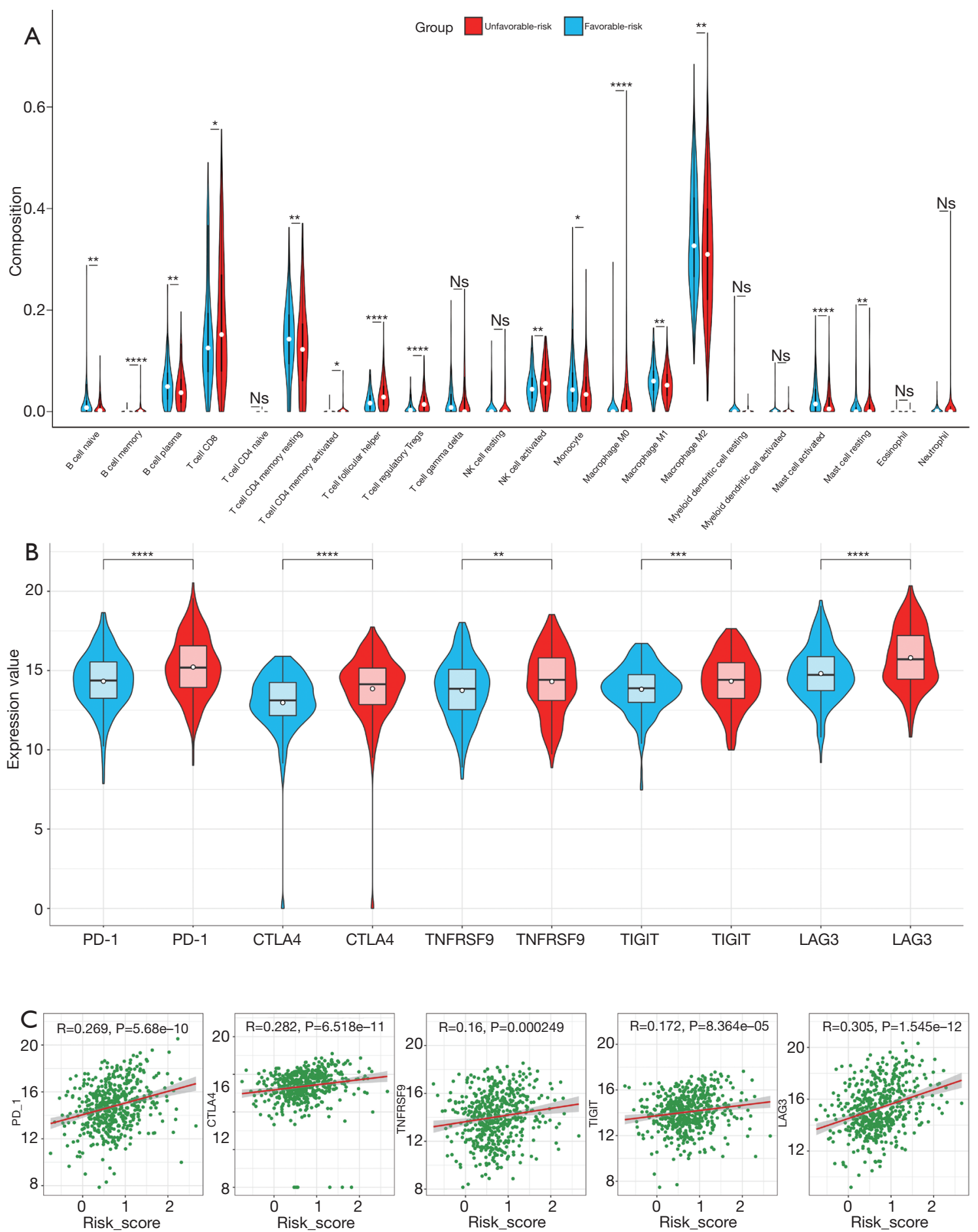

Figure 6 TME immune cell infiltration characteristics of 22 immune cell subtypes in unfavorable-risk and favorable-risk groups. (A) The violin plot of the abundance of immune cell subtypes in two groups. The asterisks on the top represented the $\mathrm{P}$ value of Wilcoxon test (ns $\mathrm{P}>0.05 ;{ }^{*} \mathrm{P}<0.05 ;{ }^{*} \mathrm{P}<0.01 ;{ }^{* *} \mathrm{P}<0.001 ;{ }^{* * *} \mathrm{P}<0.0001$ ). (B) The violin plot of the expression of $\mathrm{T}$ cell exhaustion-related markers and common immune checkpoint in two groups. (C) Spearman correlation analysis of risk score and above markers. 

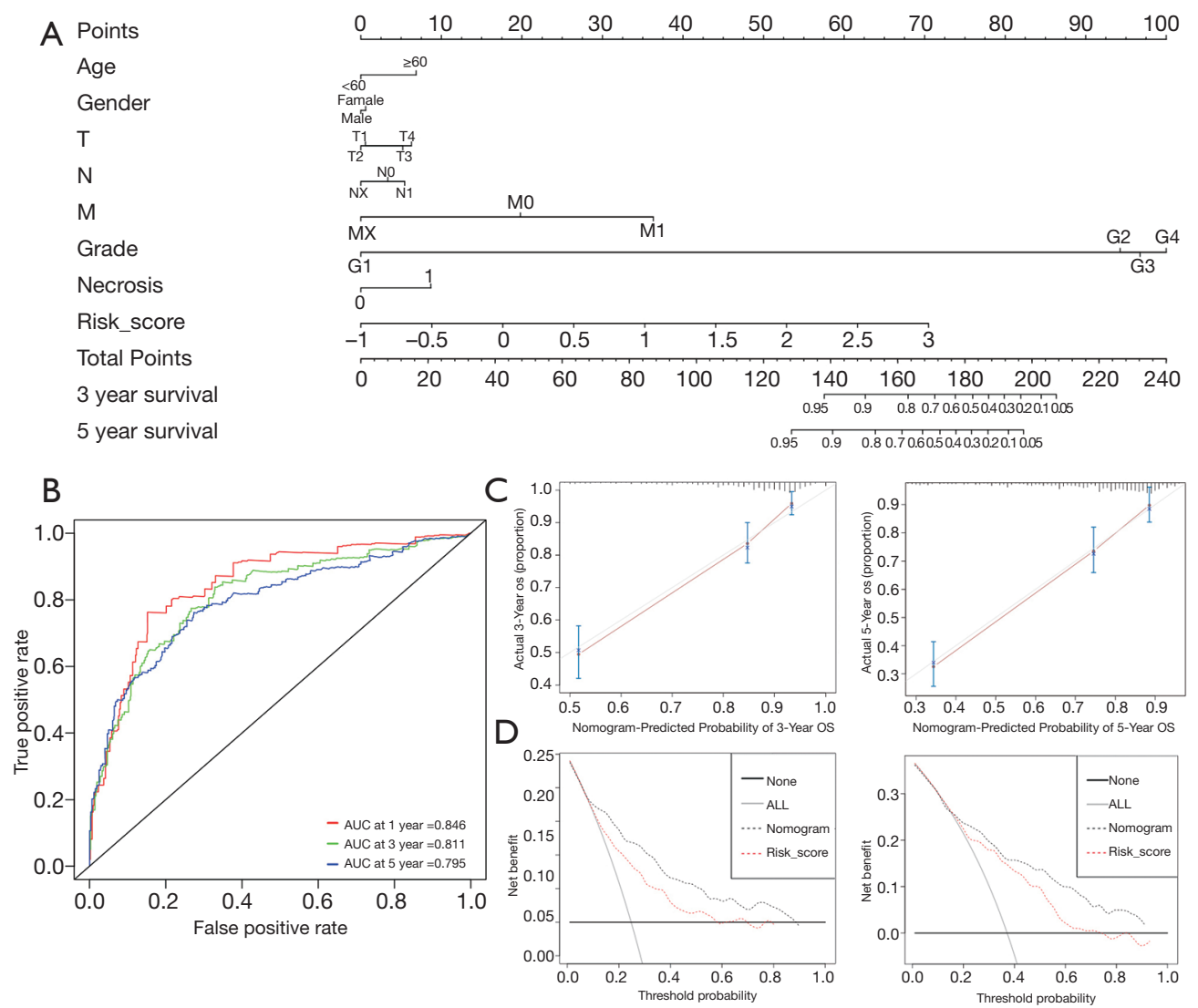

Figure 7 Construction and validation of the nomogram in TCGA-KIRC cohort. (A) The clinical nomogram of the ccRCC patients (TCGA cohort). (B) The ROC curves of nomogram for predicting OS in training set and the AUC of 1, 3, 5-year. (C) The 3-year and 5-year calibration curves of the nomogram in training set. (D) The 3-year and 5-year DCA plots of the nomogram. The grey, red dotted lines respectively represent net benefits of nomogram and risk score at different threshold probabilities.

colorectal, lung and bladder cancers (22-25). In this study, we screened and validated CRABP2, LTB4R, PTGER1 and TEK from TCGA database as potent IRGs to predict the survival risk in ccRCC patients. Multivariate Cox proportional hazards models were constructed to stratify patients based on the 4 genes signature. Laboratory q-PCR confirmed LTB4R upregulated and CRABP2, PTGER1, TEK downregulated in 35 pairs of ccRCC and normal tissues.

LTB4R is a receptor of Leukotriene B4 and is expressed mainly in leukocytes like granulocytes, macrophages and eosinophils (26). Several studies implied it was involved in CD8 T cells recruiting $(27,28)$. The neutrophilic influx induced by LTB4 increases the pro-tumorigenic activity of tumor-associated neutrophils through releasing reactive oxygen species, inflammatory cytokines and injuring innate immune response $(29,30)$. CRABP2 was responding in retinoic acid (RA) transduction as a tumor suppressive pathway (31). However, artificially overexpressing CRABP2 in Caki-2 cells did not exhibit a significant change in RA sensitivity. Our data indicated CRABP2 was lowly expressed in ccRCC samples, which was consistent with previous study (32). Although the exactly role of CRABP2 in RCC is not clear yet, our data showed high CARBP2 expression was an independent predictor factor for worse prognosis. Further investigations are necessary to define other molecules involved in CARBP2 mediated RA signaling and metabolism in RCC. PTGER1 is one of the receptors of prostaglandin and it couples with G-proteins to activate protein kinase C (33). Previous study implied blocking PTGER1 could suppress immunosuppressive function of Treg and subsequently inhibit tumor growth in colon cancer (34). In ccRCC, our result also exhibited high PTGER1 expression was correlated with worse prognosis. 
TEK encodes Tie2, which cooperate with VEGFs as critical regulators of vascular development (35). Actually, mechanisms of angiogenesis are extremely complex depending on different tumor stage and content, therefore, the prediction role of Tie2 is inconsistent among different tumor types (36). Increasing Tie2 expression correlated with high metastasis risk and poor survival among breast cancer and glioblastoma patients $(37,38)$. However, in ccRCC, our data implied downregulation of TEK associated with a poor prognosis which was also demonstrated in previous studies $(39,40)$. Low expression of TEK has been noted in aggressive ccRCC for years (41). Recently, when compared gene prevalence between nonmetastatic and metastatic ccRCC by target next generation sequencing from 106 sporadic cases, higher frequencies of TEK mutations involved in metastatic cohort (42). Since Tie2 signaling influences vascular permeability, low expression of Tie2 may potentiate inflammatory cells migration into tumor microenvironment (43). Inflammatory cytokines such as TNF- $\alpha$, IL-6, CXCL8 induces a more aggressive tumor phenotype via immune surveillance and form premetastatic niche. Overall, we assume TEK is a tumor suppressor in ccRCC, further studies are needed in future.

Solid tumors usually disrupt tumor target immune response by subvert immune surveillance. Tumor immune signature is highly correlated with tumor prognosis and response to immunotherapy. When using a 34-gene expression signature, ccRCC can be characterized into high angiogenesis tumor with improved prognosis or high immunocytes tumor with worse survival (44). Tumor infiltrating lymphocytes in ccRCC were analyzed by gene expression and cytometry phenotyping, the result implied more poorly cytotoxic CD8 T cell, Treg infiltrate in unfavorable risk group (45). In this current study, we also investigated high proportion of CD8 T cell, Treg, NK cell in unfavorable risk group through CIBERSORT algorithm, which indicated that our novel prediction model could properly distinct patient into different immunological features. Besides, a group of immunomodulators (PD-1, CTLA4, TNFRSF9, TIGIT and LAG3) was significantly correlated with our risk score, and confirmed our risk model stably stratified patients from immune evasion perspective.

In order to increase prediction accuracy, we developed a clinical nomogram with age, gender, TNM stage, Fuhrman grade, necrosis and risk score. This nomogram obtained an AUC of $0.846,0.811$ and 0.795 in predicting the possibility of survival at 1-, 3- and 5-year respectively. As there is lack of Fuhrman grade, necrosis information in ICGC database, we removed these two factors from original nomogram for validation. The modified nomogram consistently obtained a relatively high AUC of $0.755,0.728$ and 0.713 in survival prediction at 1-, 3- and 5-year separately in ICGC data. Hence, based on the 4 immune related genes $C R A B P 2$, LTB4R, PTGER1 and TEK, we successfully constructed a prognostic risk model for ccRCC and externally validated its accuracy. Defective T-cells and aberrant expression suppressive immunomodulators lead tumor be more aggressive. Owing to data we obtained from public database, further independent validation in prospective studies is needed.

\section{Acknowledgments}

English Language Editor: Dr. M. Mumin.

Funding: Our work was supported by National Natural Science Foundation of China (No. 81202011, 81572522); Science and Technology Planning Project of Guangdong Province, China (No. 2016A020215235); Pearl River Nova Program of Guangzhou, China (No. 201710010057).

\section{Footnote}

Reporting Checklist: The authors have completed the TRIPOD reporting checklist. Available at http://dx.doi. org/10.21037/tau-20-1348

Data Sharing Statement: Available at http://dx.doi. org/10.21037/tau-20-1348

Peer Review File: Available at http://dx.doi.org/10.21037/ tau-20-1348

Conflicts of Interest: All authors have completed the ICMJE uniform disclosure form (available at http://dx.doi. org/10.21037/tau-20-1348). The authors have no conflicts of interest to declare.

Ethical Statement: The authors are accountable for all aspects of the work in ensuring that questions related to the accuracy or integrity of any part of the work are appropriately investigated and resolved. All procedures performed in this study were in accordance with the Declaration of Helsinki (as revised in 2013).

Open Access Statement: This is an Open Access article distributed in accordance with the Creative Commons 
Attribution-NonCommercial-NoDerivs 4.0 International License (CC BY-NC-ND 4.0), which permits the noncommercial replication and distribution of the article with the strict proviso that no changes or edits are made and the original work is properly cited (including links to both the formal publication through the relevant DOI and the license). See: https://creativecommons.org/licenses/by-nc-nd/4.0/.

\section{References}

1. Bray F, Ferlay J, Soerjomataram I, et al. Global cancer statistics 2018: GLOBOCAN estimates of incidence and mortality worldwide for 36 cancers in 185 countries. CA Cancer J Clin 2018;68:394-424.

2. Gupta K, Miller JD, Li JZ, et al. Epidemiologic and socioeconomic burden of metastatic renal cell carcinoma (mRCC): a literature review. Cancer Treat Rev 2008;34:193-205.

3. Rini B, Goddard A, Knezevic D, et al. A 16-gene assay to predict recurrence after surgery in localised renal cell carcinoma: development and validation studies. Lancet Oncol 2015;16:676-85.

4. Brooks SA, Brannon AR, Parker JS, et al. ClearCode34: A prognostic risk predictor for localized clear cell renal cell carcinoma. Eur Urol 2014;66:77-84.

5. Bukowski RM. Natural history and therapy of metastatic renal cell carcinoma: the role of interleukin-2. Cancer 1997;80:1198-220.

6. Motzer RJ, Bacik J, Murphy BA, et al. Interferon-alfa as a comparative treatment for clinical trials of new therapies against advanced renal cell carcinoma. J Clin Oncol 2002;20:289-96.

7. Rini BI, Plimack ER, Stus V, et al. Pembrolizumab plus Axitinib versus Sunitinib for Advanced Renal-Cell Carcinoma. N Engl J Med 2019;380:1116-27.

8. Motzer RJ, Penkov K, Haanen J, et al. Avelumab plus Axitinib versus Sunitinib for Advanced Renal-Cell Carcinoma. N Engl J Med 2019;380:1103-15.

9. Chen YP, Wang YQ, Lv JW, et al. Identification and validation of novel microenvironment-based immune molecular subgroups of head and neck squamous cell carcinoma: implications for immunotherapy. Ann Oncol 2019;30:68-75.

10. Ji RR, Chasalow SD, Wang L, et al. An immuneactive tumor microenvironment favors clinical response to ipilimumab. Cancer Immunol Immunother 2012;61:1019-31.

11. Phipson B, Lee S, Majewski IJ, et al. Robust
Hyperparameter Estimation Protects against Hypervariable Genes and Improves Power to Detect Differential Expression. Ann Appl Stat 2016;10:946-63.

12. Ritchie ME, Phipson B, Wu D, et al. limma powers differential expression analyses for RNA-sequencing and microarray studies. Nucleic Acids Res 2015;43:e47.

13. Huang $\mathrm{R}$, Liao $X$, Li Q. Identification and validation of potential prognostic gene biomarkers for predicting survival in patients with acute myeloid leukemia. Onco Targets Ther 2017;10:5243-54.

14. Zhou M, Zhao H, Wang Z, et al. Identification and validation of potential prognostic lncRNA biomarkers for predicting survival in patients with multiple myeloma. J Exp Clin Cancer Res 2015;34:102.

15. Heagerty PJ, Zheng Y. Survival model predictive accuracy and ROC curves. Biometrics 2005;61:92-105.

16. Newman AM, Liu CL, Green MR, et al. Robust enumeration of cell subsets from tissue expression profiles. Nat Methods 2015;12:453-7.

17. Li T, Fan J, Wang B, et al. TIMER: A Web Server for Comprehensive Analysis of Tumor-Infiltrating Immune Cells. Cancer Res 2017;77:e108-10.

18. Balachandran VP, Gonen M, Smith JJ, et al. Nomograms in oncology: more than meets the eye. Lancet Oncol 2015;16:e173-80.

19. Xu WH, Shi SN, Xu Y, et al. Prognostic implications of Aquaporin 9 expression in clear cell renal cell carcinoma. J Transl Med 2019;17:363.

20. Du GW, Yan X, Chen Z, et al. Identification of transforming growth factor beta induced (TGFBI) as an immune-related prognostic factor in clear cell renal cell carcinoma (ccRCC). Aging (Albany NY) 2020;12:8484-505.

21. Wu T, Dai Y. Tumor microenvironment and therapeutic response. Cancer Lett 2017;387:61-8.

22. Luo C, Lei M, Zhang Y, et al. Systematic construction and validation of an immune prognostic model for lung adenocarcinoma. J Cell Mol Med 2020;24:1233-44.

23. Qiu H, Hu X, He C, et al. Identification and Validation of an Individualized Prognostic Signature of Bladder Cancer Based on Seven Immune Related Genes. Front Genet 2020;11:12.

24. Wang Z, Zhu J, Liu Y, et al. Development and validation of a novel immune-related prognostic model in hepatocellular carcinoma. J Transl Med 2020;18:67.

25. Zhao X, Liu J, Liu S, et al. Construction and Validation of an Immune-Related Prognostic Model Based on TP53 Status in Colorectal Cancer. Cancers (Basel) 2019;11:1722.

26. Tager AM, Luster AD. BLT1 and BLT2: the leukotriene 
B(4) receptors. Prostaglandins Leukot Essent Fatty Acids 2003;69:123-34.

27. Chheda ZS, Sharma RK, Jala VR, et al. Chemoattractant Receptors BLT1 and CXCR3 Regulate Antitumor Immunity by Facilitating CD8+ T Cell Migration into Tumors. J Immunol 2016;197:2016-26.

28. Sharma RK, Chheda Z, Jala VR, et al. Expression of leukotriene $\mathrm{B}(4)$ receptor- 1 on $\mathrm{CD} 8(+)$ T cells is required for their migration into tumors to elicit effective antitumor immunity. J Immunol 2013;191:3462-70.

29. Galdiero MR, Garlanda C, Jaillon S, et al. Tumor associated macrophages and neutrophils in tumor progression. J Cell Physiol 2013;228:1404-12.

30. Fridlender ZG, Sun J, Kim S, et al. Polarization of tumorassociated neutrophil phenotype by TGF-beta: "N1" versus "N2" TAN. Cancer Cell 2009;16:183-94.

31. Fu YS, Wang Q, Ma JX, et al. CRABP-II methylation: a critical determinant of retinoic acid resistance of medulloblastoma cells. Mol Oncol 2012;6:48-61.

32. Goelden U, Pfoertner S, Hansen W, et al. Expression and functional influence of cellular retinoic acid-binding protein II in renal cell carcinoma. Urol Int 2005;75:269-76.

33. Sugimoto Y, Narumiya S. Prostaglandin E receptors. J Biol Chem 2007;282:11613-7.

34. O'Callaghan G, Ryan A, Neary P, et al. Targeting the EP1 receptor reduces Fas ligand expression and increases the antitumor immune response in an in vivo model of colon cancer. Int J Cancer 2013;133:825-34.

35. Ramsauer M, D'Amore PA. Getting Tie(2)d up in angiogenesis. J Clin Invest 2002;110:1615-7.

36. Sharma S, Sharma MC, Sarkar C. Morphology of angiogenesis in human cancer: a conceptual overview, histoprognostic perspective and significance of

Cite this article as: Liao Z, Yao H, Wei J, Feng Z, Chen W, Luo J, Chen X. Development and validation of the prognostic value of the immune-related genes in clear cell renal cell carcinoma. Transl Androl Urol 2021;10(4):1607-1619. doi: $10.21037 /$ tau-20-1348 neoangiogenesis. Histopathology 2005;46:481-9.

37. Dales JP, Garcia S, Bonnier P, et al. Tie2/Tek expression in breast carcinoma: correlations of immunohistochemical assays and long-term follow-up in a series of 909 patients. Int J Oncol 2003;22:391-7.

38. Zheng S, Tao W. Identification of Novel Transcriptome Signature as a Potential Prognostic Biomarker for AntiAngiogenic Therapy in Glioblastoma Multiforme. Cancers (Basel) 2020;12:2368.

39. Shen C, Liu J, Wang J, et al. Development and validation of a prognostic immune-associated gene signature in clear cell renal cell carcinoma. Int Immunopharmacol 2020;81:106274.

40. Ha M, Son YR, Kim J, et al. TEK is a novel prognostic marker for clear cell renal cell carcinoma. Eur Rev Med Pharmacol Sci 2019;23:1451-8.

41. Kosari F, Parker AS, Kube DM, et al. Clear cell renal cell carcinoma: gene expression analyses identify a potential signature for tumor aggressiveness. Clin Cancer Res 2005;11:5128-39.

42. Meng H, Jiang X, Cui J, et al. Genomic Analysis Reveals Novel Specific Metastatic Mutations in Chinese Clear Cell Renal Cell Carcinoma. Biomed Res Int 2020;2020:2495157.

43. Parikh SM. Angiopoietins and Tie2 in vascular inflammation. Curr Opin Hematol 2017;24:432-8.

44. Iglesia MD, Parker JS, Hoadley KA, et al. Genomic Analysis of Immune Cell Infiltrates Across 11 Tumor Types. J Natl Cancer Inst 2016;108:djw144.

45. Giraldo NA, Becht E, Vano Y, et al. Tumor-Infiltrating and Peripheral Blood T-cell Immunophenotypes Predict Early Relapse in Localized Clear Cell Renal Cell Carcinoma. Clin Cancer Res 2017;23:4416-28. 


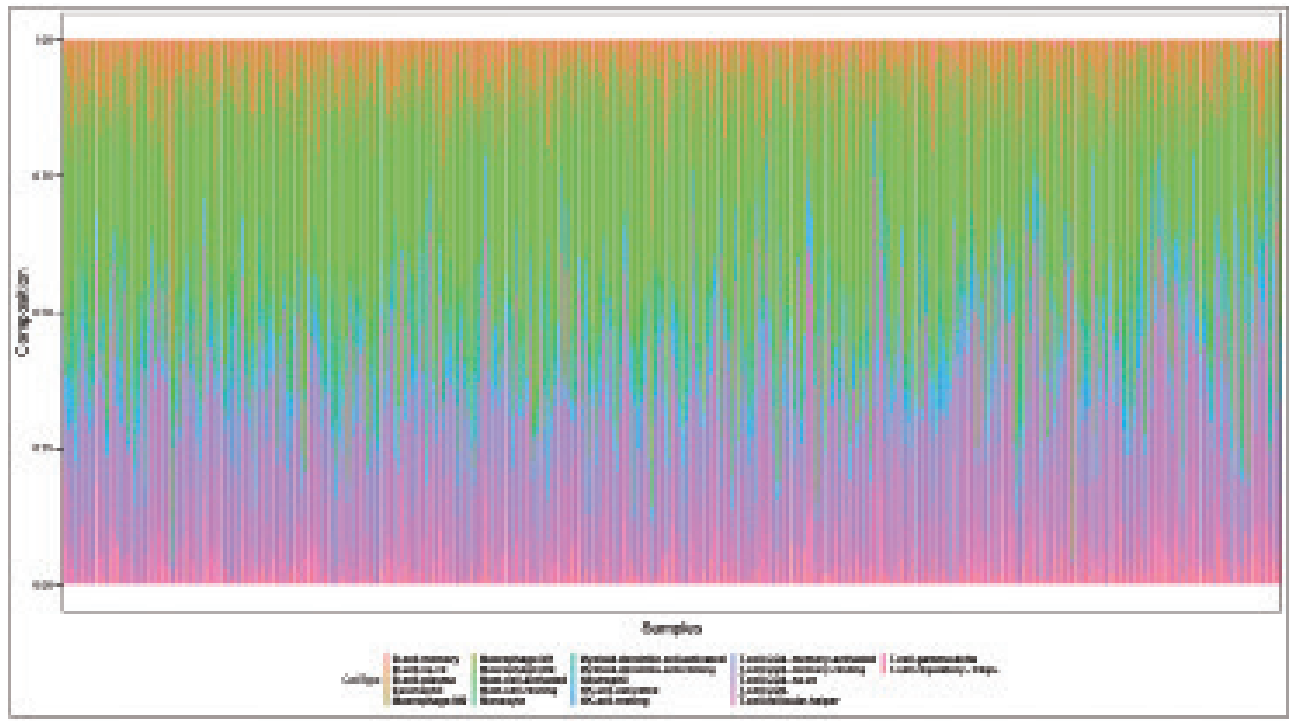

Figure S1 The summary of immune infiltration in 518 patients.
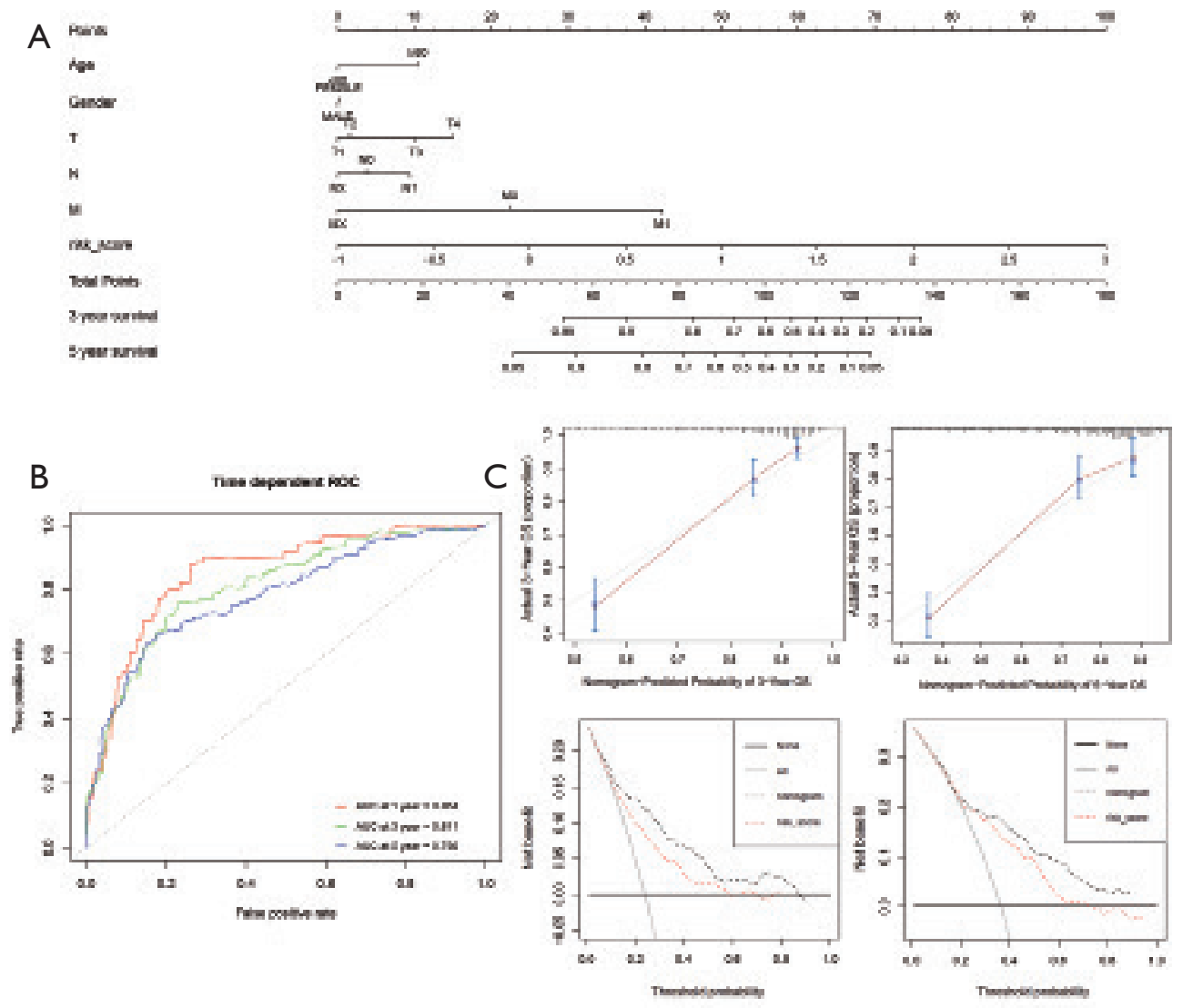

Figure S2 Construction and validation of the nomogram. (A) The clinical nomogram of the ccRCC patients (TCGA cohort). (B) The ROC curves of nomogram for predicting OS in training set and the AUC of 1, 3, 5-year. (C) The top line are the 3-year and 5-year calibration curves of the nomogram in training set; The bottom line are the 3 -year and 5-year DCA plots of the nomogram. 


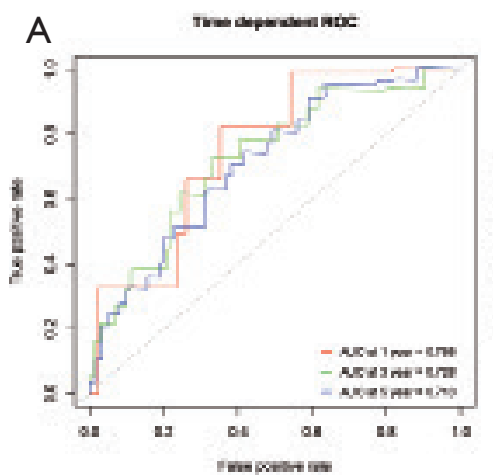

B
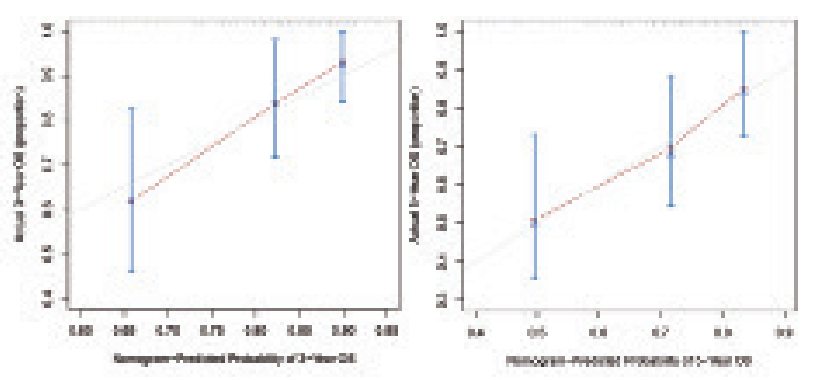

Figure S3 ROC curves for the nomogram in validation set (A) The ROC curves of nomogram for predicting OS in validation set and the AUC of 1, 3, 5-year. (B) 3-year and 5-year calibration curves of the nomogram in validation set.

Table S1 Clinical information for TCGA-KIRC dataset

\begin{tabular}{|c|c|}
\hline Variable & No. of patients \\
\hline \multicolumn{2}{|l|}{ Gender } \\
\hline Male & 335 \\
\hline Female & 183 \\
\hline \multicolumn{2}{|l|}{ Age } \\
\hline$\geq 60$ & 278 \\
\hline$<60$ & 240 \\
\hline \multicolumn{2}{|c|}{ Histological grade } \\
\hline G1 & 13 \\
\hline G2 & 220 \\
\hline G3 & 204 \\
\hline G4 & 73 \\
\hline $\mathrm{Gx}$ & 5 \\
\hline Not available & 3 \\
\hline \multicolumn{2}{|l|}{ Stage } \\
\hline I & 257 \\
\hline II & 56 \\
\hline III & 123 \\
\hline IV & 82 \\
\hline \multicolumn{2}{|l|}{ T stage } \\
\hline I & 263 \\
\hline II & 68 \\
\hline III & 176 \\
\hline IV & 11 \\
\hline \multicolumn{2}{|l|}{$\mathrm{N}$ stage } \\
\hline NO & 237 \\
\hline $\mathrm{N} 1$ & 15 \\
\hline $\mathrm{Nx}$ & 266 \\
\hline \multicolumn{2}{|l|}{ M stage } \\
\hline MO & 430 \\
\hline M1 & 79 \\
\hline$M x$ & 9 \\
\hline
\end{tabular}

Table S2 Clinical information for ICGC dataset

\begin{tabular}{|c|c|}
\hline Variable & No. of patients \\
\hline \multicolumn{2}{|l|}{ Gender } \\
\hline Male & 52 \\
\hline Female & 39 \\
\hline \multicolumn{2}{|l|}{ Age } \\
\hline$\geq 60$ & 52 \\
\hline$<60$ & 39 \\
\hline \multicolumn{2}{|c|}{ Histological grade } \\
\hline G1 & 13 \\
\hline G2 & 48 \\
\hline G3 & 15 \\
\hline G4 & 14 \\
\hline Not available & 1 \\
\hline \multicolumn{2}{|l|}{ Stage } \\
\hline । & 53 \\
\hline II & 13 \\
\hline III & 16 \\
\hline IV & 9 \\
\hline \multicolumn{2}{|l|}{ T stage } \\
\hline I & 54 \\
\hline II & 13 \\
\hline III & 22 \\
\hline IV & 2 \\
\hline \multicolumn{2}{|l|}{$\mathrm{N}$ stage } \\
\hline No & 79 \\
\hline $\mathrm{N} 1$ & 2 \\
\hline $\mathrm{Nx}$ & 10 \\
\hline \multicolumn{2}{|l|}{ M stage } \\
\hline Mo & 81 \\
\hline M1 & 9 \\
\hline$M x$ & 1 \\
\hline
\end{tabular}


Table S3 Primer sequences for qRT-PCR

\begin{tabular}{ll}
\hline CRABP2-F & ATCGGAAAACTTCGAGGAATTGC \\
\hline CRABP2-R & AGGCTCTTACAGGGCCTCC \\
LTB4R-F & AGCTTTGGGTGTGGAGTATCC \\
LTB4R-R & GCAACCAGCCAGTCCAAAAC \\
PTGER1-F & CACCTTCTTTGGCGGCTCTC \\
PTGER1-R & GATGCACGACACCACCATG \\
TEK-F & TCCGCTGGAAGTACTCAAGA \\
TEK-R & GAACTCGCCCTTCACAGAAATAA \\
\hline
\end{tabular}

Table S4 Information for the 382 IRDEGs

\begin{tabular}{|c|c|}
\hline Gene & Group \\
\hline$C D 1 D$ & Up-regulated gene \\
\hline$C D 4$ & Up-regulated gene \\
\hline$C D 8 A$ & Up-regulated gene \\
\hline$C D 8 B$ & Up-regulated gene \\
\hline$C D 74$ & Up-regulated gene \\
\hline CTSE & Up-regulated gene \\
\hline CTSS & Up-regulated gene \\
\hline FCER1G & Up-regulated gene \\
\hline$H L A-A$ & Up-regulated gene \\
\hline$H L A-B$ & Up-regulated gene \\
\hline$H L A-D O B$ & Up-regulated gene \\
\hline$H L A-D P A 1$ & Up-regulated gene \\
\hline$H L A-D P B 1$ & Up-regulated gene \\
\hline$H L A-D Q A 1$ & Up-regulated gene \\
\hline$H L A-D Q A 2$ & Up-regulated gene \\
\hline$H L A-D Q B 1$ & Up-regulated gene \\
\hline HLA-DRA & Up-regulated gene \\
\hline$H L A-D R B 1$ & Up-regulated gene \\
\hline$H L A-F$ & Up-regulated gene \\
\hline$H L A-G$ & Up-regulated gene \\
\hline HSPA2 & Down-regulated gene \\
\hline HSPAG & Up-regulated gene \\
\hline IFNA14 & Down-regulated gene \\
\hline IFNG & Up-regulated gene \\
\hline KIR2DL1 & Up-regulated gene \\
\hline KIR2DL3 & Up-regulated gene \\
\hline KIR2DL4 & Up-regulated gene \\
\hline KIR3DL1 & Up-regulated gene \\
\hline KIR3DL2 & Up-regulated gene \\
\hline$K L R C 1$ & Up-regulated gene \\
\hline KLRC2 & Up-regulated gene \\
\hline$K L R D 1$ & Up-regulated gene \\
\hline LTA & Up-regulated gene \\
\hline PSMB8 & Up-regulated gene \\
\hline TAP1 & Up-regulated gene \\
\hline TAPBP & Up-regulated gene \\
\hline$K L R C 4$ & Up-regulated gene \\
\hline IFI30 & Up-regulated gene \\
\hline PROCR & Up-regulated gene \\
\hline RAET1E & Down-regulated gene \\
\hline RAET1L & Down-regulated gene \\
\hline HAMP & Up-regulated gene \\
\hline SLPI & Down-regulated gene \\
\hline CXCL10 & Up-regulated gene \\
\hline CXCL9 & Up-regulated gene \\
\hline CXCL5 & Up-regulated gene \\
\hline CXCL11 & Up-regulated gene \\
\hline CXCL13 & Up-regulated gene \\
\hline$X C L 1$ & Up-regulated gene \\
\hline$D E F B 1$ & Down-regulated gene \\
\hline TMSB10 & Up-regulated gene \\
\hline LCN2 & Down-regulated gene \\
\hline$B P I$ & Down-regulated gene \\
\hline
\end{tabular}

Table S4 (continued)
Table S4 (continued)

\begin{tabular}{ll}
\hline Gene & Group \\
\hline S100A8 & Up-regulated gene \\
PTGDS & Down-regulated gene \\
PGLYRP2 & Up-regulated gene \\
S100A2 & Down-regulated gene \\
DEFB125 & Down-regulated gene \\
DEFB132 & Down-regulated gene \\
S100A5 & Down-regulated gene \\
$T M S B 4 Y$ & Down-regulated gene \\
$T M S B 15 B$ & Up-regulated gene
\end{tabular}

TMSB15B

Up-regulated gene

S100A14 Down-regulated gene

AZU1 Up-regulated gene

WFDC2 Down-regulated gene

UMODL1 Down-regulated gene

TGFB1 Up-regulated gene

MMP9 Up-regulated gene

APOBEC3G Up-regulated gene

FABP6 Up-regulated gene

NOD2 Up-regulated gene

MBL2 Up-regulated gene

TLR2 Up-regulated gene

PLAU Down-regulated gene

PAEP Up-regulated gene

$\angle P A \quad$ Down-regulated gene

RBP4 Down-regulated gene

LTF Down-regulated gene

FABP7 Up-regulated gene

FABP5 Up-regulated gene

OASL Up-regulated gene

CRABP2 Down-regulated gene

CRABP1 Down-regulated gene

RBP2 Down-regulated gene

$P M P 2 \quad$ Down-regulated gene

$A P O D \quad$ Down-regulated gene

PRTN3 Up-regulated gene

CYBB Up-regulated gene

ISG2O Up-regulated gene

DUOX2 Down-regulated gene

IDO1 Up-regulated gene

SEMG1 Down-regulated gene

CCL2O Up-regulated gene

CHIT1 Up-regulated gene

CD40 Up-regulated gene

TLR7 Up-regulated gene

VEGFA Up-regulated gene

ISG15 Up-regulated gene

TFR2 Up-regulated gene

IL27 Up-regulated gene

LYZ Up-regulated gene

CCL5 Up-regulated gene

CCR6 Up-regulated gene

TLR8 Up-regulated gene

GNLY Up-regulated gene

PDGFRA Down-regulated gene

MSR1 Up-regulated gene

DLL4 Up-regulated gene

SLC11A1 Up-regulated gene

SEMG2 Down-regulated gene

DES Down-regulated gene

TNFRSF1OB Up-regulated gene

CCL4 Up-regulated gene

APOBEC $3 \mathrm{H} \quad$ Up-regulated gene

TMPRSS6 Up-regulated gene

Table S4 (continued) 
Table S4 (continued)

\begin{tabular}{|c|c|}
\hline Gene & Group \\
\hline MARCO & Up-regulated gene \\
\hline KNG1 & Down-regulated gene \\
\hline KLRK1 & Up-regulated gene \\
\hline RNASE3 & Up-regulated gene \\
\hline IRF7 & Up-regulated gene \\
\hline LTB4R & Up-regulated gene \\
\hline IL7R & Up-regulated gene \\
\hline АРОВЕСЗС & Up-regulated gene \\
\hline PTGS2 & Down-regulated gene \\
\hline CDAOLG & Up-regulated gene \\
\hline CD14 & Up-regulated gene \\
\hline MASP1 & Up-regulated gene \\
\hline PROC & Down-regulated gene \\
\hline$H R G$ & Down-regulated gene \\
\hline HMOX1 & Up-regulated gene \\
\hline STAB2 & Up-regulated gene \\
\hline$P D C D 1$ & Up-regulated gene \\
\hline PCSK2 & Down-regulated gene \\
\hline ARG2 & Down-regulated gene \\
\hline$A Q P 9$ & Up-regulated gene \\
\hline FASLG & Up-regulated gene \\
\hline$A P O H$ & Down-regulated gene \\
\hline BIRC5 & Up-regulated gene \\
\hline VIM & Up-regulated gene \\
\hline VCAM1 & Up-regulated gene \\
\hline GBP2 & Up-regulated gene \\
\hline$A L B$ & Down-regulated gene \\
\hline OAS1 & Up-regulated gene \\
\hline AGER & Up-regulated gene \\
\hline NOS1 & Down-regulated gene \\
\hline CCL18 & Up-regulated gene \\
\hline CCL22 & Up-regulated gene \\
\hline CCR7 & Up-regulated gene \\
\hline CCR8 & Up-regulated gene \\
\hline CCL21 & Down-regulated gene \\
\hline CCL3 & Up-regulated gene \\
\hline CCL11 & Down-regulated gene \\
\hline CCR5 & Up-regulated gene \\
\hline CCL3L3 & Up-regulated gene \\
\hline CCL4L1 & Up-regulated gene \\
\hline$x C L 2$ & Up-regulated gene \\
\hline CXCR4 & Up-regulated gene \\
\hline CXCR6 & Up-regulated gene \\
\hline FAM19A4 & Down-regulated gene \\
\hline FAM19A1 & Down-regulated gene \\
\hline$C D H 1$ & Down-regulated gene \\
\hline IL10 & Up-regulated gene \\
\hline CRP & Up-regulated gene \\
\hline PTGDR & Up-regulated gene \\
\hline$C D 86$ & Up-regulated gene \\
\hline HCK & Up-regulated gene \\
\hline$V D R$ & Down-regulated gene \\
\hline OLR1 & Up-regulated gene \\
\hline RNASE2 & Up-regulated gene \\
\hline$C D 79 A$ & Up-regulated gene \\
\hline BTK & Up-regulated gene \\
\hline VAV1 & Up-regulated gene \\
\hline RAC2 & Up-regulated gene \\
\hline CHP2 & Down-regulated gene \\
\hline CARD11 & Up-regulated gene \\
\hline CR2 & Down-regulated gene \\
\hline PIK3R5 & Up-regulated gene \\
\hline INPP5D & Up-regulated gene \\
\hline
\end{tabular}

Table S4 (continued)
Table S4 (continued)

\begin{tabular}{|c|c|}
\hline Gene & Group \\
\hline CD72 & Up-regulated gene \\
\hline LILRB3 & Up-regulated gene \\
\hline FCGR2B & Up-regulated gene \\
\hline C3 & Up-regulated gene \\
\hline EDN1 & Up-regulated gene \\
\hline EDN3 & Down-regulated gene \\
\hline FGF10 & Down-regulated gene \\
\hline SEMA3B & Down-regulated gene \\
\hline SEMA3D & Down-regulated gene \\
\hline SEMA3E & Down-regulated gene \\
\hline SEMA3G & Down-regulated gene \\
\hline SEMA5B & Up-regulated gene \\
\hline SEMA6A & Up-regulated gene \\
\hline SEMA6B & Up-regulated gene \\
\hline SEMA6D & Down-regulated gene \\
\hline SLIT2 & Down-regulated gene \\
\hline TYMP & Up-regulated gene \\
\hline CCR9 & Down-regulated gene \\
\hline CX3CR1 & Up-regulated gene \\
\hline CXCR3 & Up-regulated gene \\
\hline FPR1 & Up-regulated gene \\
\hline LTB4R2 & Up-regulated gene \\
\hline PLAUR & Up-regulated gene \\
\hline PLXNA4 & Down-regulated gene \\
\hline PLXNB3 & Up-regulated gene \\
\hline PLXNC1 & Up-regulated gene \\
\hline PLXND1 & Up-regulated gene \\
\hline XCR1 & Up-regulated gene \\
\hline$A D M$ & Up-regulated gene \\
\hline$A D M 2$ & Up-regulated gene \\
\hline AGRP & Down-regulated gene \\
\hline$A M H$ & Up-regulated gene \\
\hline ANGPTL7 & Down-regulated gene \\
\hline$A P L N$ & Up-regulated gene \\
\hline$B D N F$ & Up-regulated gene \\
\hline BMP1 & Up-regulated gene \\
\hline BMP3 & Down-regulated gene \\
\hline BMP5 & Down-regulated gene \\
\hline BMP6 & Down-regulated gene \\
\hline$B M P 7$ & Down-regulated gene \\
\hline BTC & Down-regulated gene \\
\hline CALCA & Down-regulated gene \\
\hline CD70 & Up-regulated gene \\
\hline$C G A$ & Down-regulated gene \\
\hline CGB7 & Up-regulated gene \\
\hline CHGA & Down-regulated gene \\
\hline$C H G B$ & Down-regulated gene \\
\hline СМТМЗ & Up-regulated gene \\
\hline CMTM4 & Down-regulated gene \\
\hline EB/3 & Up-regulated gene \\
\hline EGF & Down-regulated gene \\
\hline EPGN & Down-regulated gene \\
\hline$E P O$ & Up-regulated gene \\
\hline ESM1 & Up-regulated gene \\
\hline FAM3B & Down-regulated gene \\
\hline FGF1 & Down-regulated gene \\
\hline FGF2O & Up-regulated gene \\
\hline FGF7 & Down-regulated gene \\
\hline FGF9 & Down-regulated gene \\
\hline GDF6 & Up-regulated gene \\
\hline GDF7 & Down-regulated gene \\
\hline GDNF & Down-regulated gene \\
\hline GMFG & Up-regulated gene \\
\hline
\end{tabular}

Table S4 (continued) 
Table S4 (continued)

\begin{tabular}{|c|c|}
\hline Gene & Group \\
\hline GNRH1 & Up-regulated gene \\
\hline GREM1 & Down-regulated gene \\
\hline GREM2 & Down-regulated gene \\
\hline IGF2 & Down-regulated gene \\
\hline IL11 & Down-regulated gene \\
\hline IL16 & Up-regulated gene \\
\hline IL19 & Down-regulated gene \\
\hline IL24 & Up-regulated gene \\
\hline IL32 & Up-regulated gene \\
\hline INHBB & Up-regulated gene \\
\hline INHBE & Up-regulated gene \\
\hline JAG2 & Up-regulated gene \\
\hline KITLG & Down-regulated gene \\
\hline$K L$ & Down-regulated gene \\
\hline LEFTY2 & Down-regulated gene \\
\hline NGF & Up-regulated gene \\
\hline NMB & Up-regulated gene \\
\hline NODAL & Up-regulated gene \\
\hline NPPA & Up-regulated gene \\
\hline NRG3 & Up-regulated gene \\
\hline OGN & Down-regulated gene \\
\hline OSM & Up-regulated gene \\
\hline PDGFD & Up-regulated gene \\
\hline$P G F$ & Up-regulated gene \\
\hline $\mathrm{PMCH}$ & Up-regulated gene \\
\hline PTHLH & Up-regulated gene \\
\hline REG1A & Up-regulated gene \\
\hline RETN & Up-regulated gene \\
\hline SCG2 & Up-regulated gene \\
\hline STC2 & Up-regulated gene \\
\hline TAC1 & Down-regulated gene \\
\hline TDGF1 & Down-regulated gene \\
\hline TNFSF13B & Up-regulated gene \\
\hline TNFSF14 & Up-regulated gene \\
\hline TNFSF8 & Up-regulated gene \\
\hline TNFSF9 & Up-regulated gene \\
\hline TSLP & Down-regulated gene \\
\hline UCN & Up-regulated gene \\
\hline UTS2 & Up-regulated gene \\
\hline VIP & Up-regulated gene \\
\hline ACVR1C & Down-regulated gene \\
\hline ADCYAP1R1 & Up-regulated gene \\
\hline$A D R B 1$ & Down-regulated gene \\
\hline ANGPTL1 & Down-regulated gene \\
\hline ANGPTL3 & Down-regulated gene \\
\hline ANGPTL4 & Up-regulated gene \\
\hline APLNR & Up-regulated gene \\
\hline AVPR1B & Up-regulated gene \\
\hline AVPR2 & Down-regulated gene \\
\hline BMPR1B & Down-regulated gene \\
\hline C3AR1 & Up-regulated gene \\
\hline CNTFR & Down-regulated gene \\
\hline CRLF2 & Up-regulated gene \\
\hline CSF1R & Up-regulated gene \\
\hline CSF2RA & Up-regulated gene \\
\hline CSF3R & Up-regulated gene \\
\hline ESRRB & Down-regulated gene \\
\hline ESRRG & Down-regulated gene \\
\hline FLT1 & Up-regulated gene \\
\hline GCGR & Down-regulated gene \\
\hline HTR3B & Down-regulated gene \\
\hline HTR3D & Down-regulated gene \\
\hline IL10RA & Up-regulated gene \\
\hline
\end{tabular}

Table S4 (continued)
Table S4 (continued)

\begin{tabular}{|c|c|}
\hline Gene & Group \\
\hline IL12RB1 & Up-regulated gene \\
\hline IL17RE & Down-regulated gene \\
\hline IL18RAP & Up-regulated gene \\
\hline IL1RL1 & Down-regulated gene \\
\hline IL2ORA & Down-regulated gene \\
\hline IL2ORB & Up-regulated gene \\
\hline IL21R & Up-regulated gene \\
\hline IL2RA & Up-regulated gene \\
\hline IL2RB & Up-regulated gene \\
\hline$I L 2 R G$ & Up-regulated gene \\
\hline IL4R & Up-regulated gene \\
\hline IL5RA & Down-regulated gene \\
\hline IL9R & Up-regulated gene \\
\hline LGR5 & Down-regulated gene \\
\hline MCHR1 & Up-regulated gene \\
\hline MTNR1A & Down-regulated gene \\
\hline NGFR & Up-regulated gene \\
\hline NROB2 & Down-regulated gene \\
\hline$N R 1 / 3$ & Down-regulated gene \\
\hline NR2E1 & Up-regulated gene \\
\hline NR3C2 & Down-regulated gene \\
\hline NRP2 & Up-regulated gene \\
\hline OPRD1 & Up-regulated gene \\
\hline OSMR & Up-regulated gene \\
\hline PRLR & Down-regulated gene \\
\hline PTGER1 & Down-regulated gene \\
\hline PTGER3 & Down-regulated gene \\
\hline PTGFR & Down-regulated gene \\
\hline PTH1R & Down-regulated gene \\
\hline RORBw & Down-regulated gene \\
\hline SORT1 & Down-regulated gene \\
\hline SSTR1 & Down-regulated gene \\
\hline SSTR5 & Down-regulated gene \\
\hline TACR1 & Down-regulated gene \\
\hline TEK & Down-regulated gene \\
\hline TGFBR3 & Down-regulated gene \\
\hline THRB & Down-regulated gene \\
\hline TNFRSF14 & Up-regulated gene \\
\hline TNFRSF18 & Up-regulated gene \\
\hline TNFRSF25 & Up-regulated gene \\
\hline TNFRSF4 & Up-regulated gene \\
\hline TNFRSF9 & Up-regulated gene \\
\hline TSHR & Up-regulated gene \\
\hline TUBB3 & Up-regulated gene \\
\hline ITGAL & Up-regulated gene \\
\hline ITGB2 & Up-regulated gene \\
\hline TYROBP & Up-regulated gene \\
\hline LCK & Up-regulated gene \\
\hline FCGR3A & Up-regulated gene \\
\hline NCR1 & Up-regulated gene \\
\hline NCR3 & Up-regulated gene \\
\hline$C D 247$ & Up-regulated gene \\
\hline ZAP70 & Up-regulated gene \\
\hline$L C P 2$ & Up-regulated gene \\
\hline$L A T$ & Up-regulated gene \\
\hline SH3BP2 & Up-regulated gene \\
\hline SHC3 & Down-regulated gene \\
\hline HCST & Up-regulated gene \\
\hline$C D 48$ & Up-regulated gene \\
\hline$C D 244$ & Up-regulated gene \\
\hline SH2D1A & Up-regulated gene \\
\hline GZMB & Up-regulated gene \\
\hline PRF1 & Up-regulated gene \\
\hline
\end{tabular}

Table S4 (continued) 
Table S4 (continued)

\begin{tabular}{ll}
\hline Gene & Group \\
\hline$C D 3 D$ & Up-regulated gene \\
$C D 3 E$ & Up-regulated gene \\
$C D 3 G$ & Up-regulated gene \\
$P T P R C$ & Up-regulated gene \\
$I T K$ & Up-regulated gene \\
GRAP2 & Up-regulated gene \\
$P A K 6$ & Down-regulated gene \\
$P A K 7$ & Down-regulated gene \\
$C D 28$ & Up-regulated gene \\
$I C O S$ & Up-regulated gene \\
$C T L A 4$ & Up-regulated gene \\
$C B L C$ & Down-regulated gene \\
$P D K 1$ & Up-regulated gene \\
$P R K C Q$ & Down-regulated gene \\
\hline
\end{tabular}

Table S5 Information for 382 differential expression IRGs identified by the univariate Cox regression analysis

\begin{tabular}{|c|c|c|c|}
\hline Gene & HR (95\% Cl) & wald.test & $P$ value \\
\hline$C D 1 D$ & $0.9971(0.8157-1.219)$ & 0.0000 & 0.9778 \\
\hline$C D 4$ & $1.069(0.901-1.269)$ & 0.5900 & 0.4431 \\
\hline$C D 8 A$ & $1.058(0.9723-1.152)$ & 1.7100 & 0.1905 \\
\hline$C D 8 B$ & $1.046(0.9626-1.136)$ & 1.1200 & 0.2896 \\
\hline$C D 74$ & $1.063(0.9098-1.242)$ & 0.5900 & 0.4413 \\
\hline CTSE & 0.9472 (0.9094-0.9865) & 6.8300 & 0.0090 \\
\hline CTSS & $0.9481(0.8173-1.1)$ & 0.4900 & 0.4821 \\
\hline FCER1G & $1.282(1.094-1.503)$ & 9.4100 & 0.0022 \\
\hline$H L A \_A$ & $1.169(0.9329-1.465)$ & 1.8400 & 0.1748 \\
\hline$H L A \_B$ & $1.027(0.8239-1.279)$ & 0.0500 & 0.8148 \\
\hline$H L A \_D O B$ & $1.094(0.9945-1.203)$ & 3.4100 & 0.0647 \\
\hline$H L A \_D P A 1$ & $0.9017(0.7874-1.032)$ & 2.2400 & 0.1343 \\
\hline HLA_DPB1 & $0.9094(0.7889-1.048)$ & 1.7200 & 0.1902 \\
\hline$H L A \_D Q A 1$ & $0.9755(0.8662-1.099)$ & 0.1700 & 0.6826 \\
\hline$H L A \_D Q A 2$ & $0.9543(0.9014-1.01)$ & 2.5900 & 0.1074 \\
\hline$H L A \_D Q B 1$ & $0.9836(0.871-1.111)$ & 0.0700 & 0.7899 \\
\hline HLA_DRA & $0.8749(0.7602-1.007)$ & 3.4800 & 0.0620 \\
\hline$H L A \_D R B 1$ & $1.051(0.8985-1.23)$ & 0.3900 & 0.5318 \\
\hline$H L A \_F$ & $1.15(0.9649-1.37)$ & 2.4300 & 0.1187 \\
\hline$H L A \_G$ & $0.9173(0.8472-0.9931)$ & 4.5400 & 0.0331 \\
\hline HSPA2 & $1.031(0.9013-1.18)$ & 0.2000 & 0.6544 \\
\hline HSPAG & $1.27(1.115-1.447)$ & 13.0000 & 0.0003 \\
\hline IFNA14 & $0.9889(0.9297-1.052)$ & 0.1300 & 0.7219 \\
\hline IFNG & $1.07(1.006-1.139)$ & 4.6500 & 0.0311 \\
\hline KIR2DL1 & $0.9837(0.9248-1.046)$ & 0.2700 & 0.6004 \\
\hline KIR2DL3 & $1.03(0.9529-1.112)$ & 0.5500 & 0.4602 \\
\hline KIR2DL4 & $1.109(0.9923-1.239)$ & 3.3300 & 0.0682 \\
\hline KIR3DL1 & $0.9636(0.9097-1.021)$ & 1.5900 & 0.2076 \\
\hline KIR3DL2 & $0.9799(0.9302-1.032)$ & 0.5800 & 0.4456 \\
\hline$K L R C 1$ & $1.054(0.9569-1.162)$ & 1.1400 & 0.2852 \\
\hline KLRC2 & $1.154(1.074-1.239)$ & 15.4500 & 0.0001 \\
\hline$K L R D 1$ & $1.087(0.909-1.299)$ & 0.8300 & 0.3612 \\
\hline LTA & $1.165(1.05-1.293)$ & 8.2600 & 0.0041 \\
\hline PSMB8 & $1.099(0.862-1.4)$ & 0.5800 & 0.4473 \\
\hline TAP1 & $1.169(0.941-1.452)$ & 1.9900 & 0.1582 \\
\hline TAPBP & $1.284(0.9955-1.656)$ & 3.7100 & 0.0542 \\
\hline KLRC4 & $1.031(0.9864-1.079)$ & 1.8500 & 0.1742 \\
\hline IFI30 & $1.409(1.262-1.574)$ & 36.9600 & 0.0000 \\
\hline PROCR & $1.087(0.9168-1.29)$ & 0.9300 & 0.3360 \\
\hline RAET1E & $0.7461(0.6457-0.8622)$ & 15.7700 & 0.0001 \\
\hline RAET1L & $1.012(0.9797-1.045)$ & 0.5100 & 0.4754 \\
\hline HAMP & $1.253(1.157-1.357)$ & 30.8400 & 0.0000 \\
\hline SLPI & $1.118(1.073-1.165)$ & 27.8200 & 0.0000 \\
\hline CXCL10 & $1.04(0.9484-1.141)$ & 0.7000 & 0.4016 \\
\hline CXCL9 & $1.038(0.95-1.134)$ & 0.6800 & 0.4107 \\
\hline
\end{tabular}

Table S5 (continued)
Table S5 (continued)

\begin{tabular}{|c|c|c|c|}
\hline Gene & HR (95\% Cl) & wald.test & $P$ value \\
\hline CXCL5 & $1.088(1.043-1.135)$ & 15.5100 & 0.0001 \\
\hline CXCL11 & $1.056(0.9667-1.152)$ & 1.4500 & 0.2283 \\
\hline CXCL13 & $1.122(1.059-1.189)$ & 15.1600 & 0.0001 \\
\hline$X C L 1$ & $1.189(1.079-1.31)$ & 12.2100 & 0.0005 \\
\hline DEFB1 & $0.9926(0.9243-1.066)$ & 0.0400 & 0.8372 \\
\hline TMSB10 & $1.37(1.158-1.62)$ & 13.5500 & 0.0002 \\
\hline LCN2 & $1.068(1.02-1.119)$ & 7.7000 & 0.0055 \\
\hline$B P I$ & $1.01(0.9278-1.101)$ & 0.0600 & 0.8107 \\
\hline S100A8 & $1.187(1.061-1.327)$ & 9.0000 & 0.0027 \\
\hline PTGDS & $1.119(1.038-1.205)$ & 8.7100 & 0.0032 \\
\hline PGLYRP2 & $1.122(1.07-1.175)$ & 23.2500 & 0.0000 \\
\hline S100A2 & $1.105(1.007-1.213)$ & 4.4700 & 0.0345 \\
\hline DEFB125 & $1.037(0.9972-1.079)$ & 3.3200 & 0.0686 \\
\hline DEFB132 & $0.9991(0.9523-1.048)$ & 0.0000 & 0.9715 \\
\hline S100A5 & $1.046(0.9721-1.125)$ & 1.4400 & 0.2295 \\
\hline TMSB4Y & $0.9835(0.9579-1.01)$ & 1.5400 & 0.2147 \\
\hline TMSB15B & $1.016(0.9259-1.116)$ & 0.1200 & 0.7337 \\
\hline$s 100 z$ & $1.062(0.9645-1.17)$ & 1.5000 & 0.2202 \\
\hline S100A14 & $1.016(0.9198-1.122)$ & 0.1000 & 0.7556 \\
\hline AZU1 & $1.048(0.9871-1.112)$ & 2.3500 & 0.1254 \\
\hline WFDC2 & $1.053(0.9824-1.13)$ & 2.1400 & 0.1437 \\
\hline UMODL1 & $1.054(1.008-1.102)$ & 5.2800 & 0.0216 \\
\hline TGFB1 & $1.438(1.167-1.772)$ & 11.6400 & 0.0006 \\
\hline MMP9 & $1.149(1.072-1.231)$ & 15.3600 & 0.0001 \\
\hline $\begin{array}{l}A P O- \\
B E C 3 G\end{array}$ & $1.322(1.131-1.546)$ & 12.2500 & 0.0005 \\
\hline FABP6 & $1.065(0.9862-1.15)$ & 2.5800 & 0.1083 \\
\hline NOD2 & $1.356(1.191-1.545)$ & 21.0200 & 0.0000 \\
\hline MBL2 & $1.066(1.033-1.099)$ & 16.3600 & 0.0001 \\
\hline TLR2 & $1.27(1.071-1.506)$ & 7.5300 & 0.0061 \\
\hline PLAU & $1.351(1.194-1.53)$ & 22.5700 & 0.0000 \\
\hline PAEP & $1.082(1.053-1.111)$ & 32.9900 & 0.0000 \\
\hline$\angle P A$ & $0.95(0.9136-0.9879)$ & 6.6100 & 0.0101 \\
\hline RBP4 & $0.9866(0.9456-1.029)$ & 0.3900 & 0.5349 \\
\hline LTF & $0.9249(0.868-0.9855)$ & 5.8100 & 0.0159 \\
\hline FABP7 & $1.013(0.975-1.054)$ & 0.4600 & 0.4980 \\
\hline FABP5 & $1.405(1.211-1.63)$ & 20.1700 & 0.0000 \\
\hline OASL & $1.333(1.168-1.521)$ & 18.1800 & 0.0000 \\
\hline CRABP2 & $1.185(1.117-1.257)$ & 31.5800 & 0.0000 \\
\hline CRABP1 & $1.026(1-1.053)$ & 3.8500 & 0.0497 \\
\hline RBP2 & $1.008(0.9633-1.055)$ & 0.1200 & 0.7311 \\
\hline PMP2 & $0.9925(0.9595-1.027)$ & 0.1900 & 0.6604 \\
\hline$A P O D$ & $1.073(0.9788-1.176)$ & 2.2600 & 0.1327 \\
\hline PRTN3 & $1.037(0.9991-1.077)$ & 3.6500 & 0.0560 \\
\hline CYBB & $0.9601(0.8561-1.077)$ & 0.4800 & 0.4866 \\
\hline ISG2O & $1.458(1.24-1.714)$ & 20.8200 & 0.0000 \\
\hline$D \cup O X 2$ & $1.056(0.9897-1.126)$ & 2.7100 & 0.0997 \\
\hline IDO1 & $0.9996(0.9032-1.106)$ & 0.0000 & 0.9941 \\
\hline SEMG1 & $1.037(0.9892-1.088)$ & 2.2900 & 0.1304 \\
\hline CCL2O & $1.048(0.9856-1.114)$ & 2.2400 & 0.1348 \\
\hline CHIT1 & $0.9889(0.9411-1.039)$ & 0.1900 & 0.6590 \\
\hline$C D 40$ & $1.149(0.9054-1.457)$ & 1.3000 & 0.2538 \\
\hline TLR7 & $0.9289(0.8339-1.035)$ & 1.7900 & 0.1804 \\
\hline VEGFA & $1.011(0.8859-1.154)$ & 0.0300 & 0.8690 \\
\hline ISG15 & $1.369(1.209-1.55)$ & 24.6000 & 0.0000 \\
\hline TFR2 & $1.134(1.059-1.213)$ & 13.1400 & 0.0003 \\
\hline IL27 & $1.169(1.059-1.291)$ & 9.5400 & 0.0020 \\
\hline$L Y Z$ & $0.8992(0.8193-0.987)$ & 4.9900 & 0.0254 \\
\hline CCL5 & $1.167(1.05-1.298)$ & 8.2100 & 0.0042 \\
\hline CCR6 & $0.9746(0.919-1.034)$ & 0.7400 & 0.3912 \\
\hline TLR8 & $0.955(0.8607-1.06)$ & 0.7500 & 0.3857 \\
\hline GNLY & $1.144(1.009-1.297)$ & 4.4100 & 0.0358 \\
\hline PDGFRA & $1.064(0.9945-1.139)$ & 3.2500 & 0.0716 \\
\hline
\end{tabular}

Table S5 (continued) 
Table S5 (continued)

\begin{tabular}{|c|c|c|c|}
\hline Gene & $\mathrm{HR}(95 \% \mathrm{Cl})$ & wald.test & $P$ value \\
\hline MSR1 & $0.9744(0.8573-1.107)$ & 0.1600 & 0.6910 \\
\hline DLL4 & $0.8588(0.7543-0.9779)$ & 5.2800 & 0.0216 \\
\hline SLC11A1 & 1.441 (1.273-1.632) & 33.1900 & 0.0000 \\
\hline SEMG2 & $1.013(0.9633-1.065)$ & 0.2600 & 0.6130 \\
\hline$D E S$ & $1.013(0.9651-1.063)$ & 0.2600 & 0.6077 \\
\hline $\begin{array}{l}\text { TNFRS- } \\
\text { F10B }\end{array}$ & $1.597(1.247-2.045)$ & 13.8000 & 0.0002 \\
\hline CCL4 & $1.138(1.01-1.282)$ & 4.5300 & 0.0333 \\
\hline АРОВЕСЗН & $1.285(1.13-1.46)$ & 14.7500 & 0.0001 \\
\hline TMPRSS6 & $1.161(1.081-1.247)$ & 16.7200 & 0.0000 \\
\hline MARCO & $1.132(1.052-1.219)$ & 10.9200 & 0.0010 \\
\hline KNG1 & $1.018(0.9809-1.056)$ & 0.8600 & 0.3527 \\
\hline KLRK1 & $1.181(1.083-1.287)$ & 14.2300 & 0.0002 \\
\hline RNASE3 & $1.018(0.9649-1.075)$ & 0.4400 & 0.5094 \\
\hline IRF7 & $1.536(1.308-1.805)$ & 27.2600 & 0.0000 \\
\hline LTB4R & $1.565(1.355-1.807)$ & 37.2900 & 0.0000 \\
\hline IL7R & $0.9419(0.8466-1.048)$ & 1.2100 & 0.2718 \\
\hline АРОВЕСЗС & $1.288(1.093-1.517)$ & 9.1800 & 0.0024 \\
\hline PTGS2 & $1.105(1.015-1.203)$ & 5.3100 & 0.0212 \\
\hline$C D 4 O L G$ & $1.009(0.9136-1.114)$ & 0.0300 & 0.8643 \\
\hline CD14 & $1.275(1.094-1.486)$ & 9.6500 & 0.0019 \\
\hline MASP1 & $0.8723(0.8134-0.9355)$ & 14.6500 & 0.0001 \\
\hline PROC & $0.986(0.9111-1.067)$ & 0.1200 & 0.7258 \\
\hline$H R G$ & $0.9921(0.9575-1.028)$ & 0.1900 & 0.6625 \\
\hline HMOX1 & $0.9387(0.8316-1.06)$ & 1.0500 & 0.3064 \\
\hline STAB2 & $1.115(1.014-1.226)$ & 5.0100 & 0.0252 \\
\hline$P D C D 1$ & $1.119(1.033-1.212)$ & 7.6800 & 0.0056 \\
\hline PCSK2 & $1.038(0.9959-1.082)$ & 3.1100 & 0.0777 \\
\hline ARG2 & $1.071(0.9916-1.157)$ & 3.0400 & 0.0810 \\
\hline AQP9 & $1.139(1.066-1.216)$ & 14.9300 & 0.0001 \\
\hline FASLG & $1.113(1.011-1.224)$ & 4.8100 & 0.0283 \\
\hline$A P O H$ & $1.058(1.012-1.106)$ & 6.3000 & 0.0121 \\
\hline BIRC5 & $1.494(1.325-1.684)$ & 43.1700 & 0.0000 \\
\hline VIM & $1.3(1.057-1.598)$ & 6.1700 & 0.0130 \\
\hline VCAM1 & $0.9496(0.868-1.039)$ & 1.2700 & 0.2590 \\
\hline GBP2 & $1.351(1.13-1.615)$ & 10.8900 & 0.0010 \\
\hline$A L B$ & $0.973(0.905-1.046)$ & 0.5500 & 0.4576 \\
\hline OAS1 & $1.105(0.9057-1.347)$ & 0.9600 & 0.3263 \\
\hline AGER & $1.368(1.209-1.549)$ & 24.6500 & 0.0000 \\
\hline NOS1 & $0.9321(0.8707-0.9979)$ & 4.0900 & 0.0432 \\
\hline CCL18 & $1.016(0.9645-1.07)$ & 0.3600 & 0.5501 \\
\hline CCL22 & $0.9097(0.8467-0.9775)$ & 6.6700 & 0.0098 \\
\hline CCR7 & $1.035(0.9234-1.161)$ & 0.3600 & 0.5510 \\
\hline CCR8 & $1.05(0.9962-1.107)$ & 3.3100 & 0.0689 \\
\hline CCL21 & $1.027(0.9862-1.07)$ & 1.6600 & 0.1978 \\
\hline CCL3 & $1.109(0.9979-1.233)$ & 3.6900 & 0.0546 \\
\hline CCL11 & $1.066(1.028-1.105)$ & 12.0900 & 0.0005 \\
\hline CCR5 & $1.052(0.9467-1.168)$ & 0.8800 & 0.3482 \\
\hline CCL3L3 & $0.9856(0.9314-1.043)$ & 0.2500 & 0.6145 \\
\hline CCL4L1 & $1.03(0.9521-1.114)$ & 0.5400 & 0.4627 \\
\hline$x C L 2$ & $1.187(1.069-1.317)$ & 10.3300 & 0.0013 \\
\hline CXCR4 & $1.182(0.9943-1.406)$ & 3.5900 & 0.0581 \\
\hline CXCR6 & $1.072(0.9571-1.202)$ & 1.4500 & 0.2287 \\
\hline FAM19A4 & $1.024(0.9874-1.061)$ & 1.6200 & 0.2027 \\
\hline FAM19A1 & $0.9818(0.9046-1.065)$ & 0.1900 & 0.6592 \\
\hline $\mathrm{CDH} 1$ & $0.7951(0.7161-0.8827)$ & 18.4600 & 0.0000 \\
\hline IL10 & $1.115(1.01-1.231)$ & 4.6300 & 0.0314 \\
\hline$C R P$ & $1.063(1.022-1.105)$ & 9.2900 & 0.0023 \\
\hline PTGDR & $1.172(1.024-1.342)$ & 5.2800 & 0.0216 \\
\hline$C D 86$ & $1.109(0.9534-1.29)$ & 1.8000 & 0.1798 \\
\hline HCK & $1.135(0.9504-1.356)$ & 1.9600 & 0.1619 \\
\hline$V D R$ & $0.9412(0.8169-1.084)$ & 0.7000 & 0.4015 \\
\hline OLR1 & $1.039(0.9317-1.159)$ & 0.4700 & 0.4919 \\
\hline
\end{tabular}

Table S5 (continued)
Table S5 (continued)

\begin{tabular}{|c|c|c|c|}
\hline Gene & $\mathrm{HR}(95 \% \mathrm{Cl})$ & wald.test & $P$ value \\
\hline RNASE2 & $1.303(1.165-1.458)$ & 21.4700 & 0.0000 \\
\hline$C D 79 A$ & $1.084(1.004-1.171)$ & 4.2200 & 0.0399 \\
\hline BTK & $1.077(0.9096-1.276)$ & 0.7500 & 0.3878 \\
\hline VAV1 & $1.159(0.992-1.354)$ & 3.4500 & 0.0631 \\
\hline RAC2 & $1.221(1.06-1.407)$ & 7.6200 & 0.0058 \\
\hline CHP2 & $1.035(0.9974-1.073)$ & 3.3100 & 0.0688 \\
\hline CARD11 & $1.193(1.074-1.325)$ & 10.8700 & 0.0010 \\
\hline CR2 & $1.003(0.9574-1.051)$ & 0.0200 & 0.8983 \\
\hline PIK3R5 & $1.105(0.9392-1.301)$ & 1.4500 & 0.2279 \\
\hline INPP5D & $1.073(0.8746-1.316)$ & 0.4600 & 0.4993 \\
\hline$C D 72$ & $1.334(1.174-1.516)$ & 19.5200 & 0.0000 \\
\hline LILRB3 & $1.47(1.268-1.704)$ & 26.0200 & 0.0000 \\
\hline FCGR2B & $1.183(1.048-1.335)$ & 7.3600 & 0.0067 \\
\hline C3 & $1.119(1.014-1.234)$ & 4.9800 & 0.0257 \\
\hline EDN1 & $0.8403(0.7657-0.9222)$ & 13.4500 & 0.0002 \\
\hline EDN3 & $1.001(0.9693-1.034)$ & 0.0000 & 0.9522 \\
\hline FGF10 & $1.023(0.9894-1.057)$ & 1.7700 & 0.1836 \\
\hline SEMA3B & $1.117(0.9971-1.252)$ & 3.6500 & 0.0562 \\
\hline SEMA3D & $0.8914(0.8435-0.9421)$ & 16.6300 & 0.0000 \\
\hline SEMA3E & $1.108(1.065-1.152)$ & 25.8800 & 0.0000 \\
\hline SEMA3G & $0.7207(0.6552-0.7928)$ & 45.3200 & 0.0000 \\
\hline SEMA5B & $0.8932(0.8186-0.9745)$ & 6.4500 & 0.0111 \\
\hline SEMA6A & $0.8171(0.7262-0.9194)$ & 11.2600 & 0.0008 \\
\hline SEMA6B & $1.01(0.8602-1.187)$ & 0.0200 & 0.9002 \\
\hline SEMA6D & $0.761(0.6714-0.8624)$ & 18.2900 & 0.0000 \\
\hline SLIT2 & $0.977(0.8853-1.078)$ & 0.2100 & 0.6436 \\
\hline TYMP & $1.434(1.21-1.698)$ & 17.3600 & 0.0000 \\
\hline CCR9 & $1.007(0.9525-1.065)$ & 0.0600 & 0.8029 \\
\hline CX3CR1 & $0.8638(0.7857-0.9496)$ & 9.1700 & 0.0025 \\
\hline CXCR3 & $1.094(0.9975-1.2)$ & 3.6400 & 0.0565 \\
\hline FPR1 & $1.026(0.9119-1.155)$ & 0.1800 & 0.6690 \\
\hline LTB4R2 & $1.367(1.177-1.587)$ & 16.7900 & 0.0000 \\
\hline PLAUR & $1.595(1.394-1.824)$ & 46.4200 & 0.0000 \\
\hline PLXNA4 & $1.124(1.03-1.228)$ & 6.8200 & 0.0090 \\
\hline PLXNB3 & $1.393(1.275-1.521)$ & 54.1500 & 0.0000 \\
\hline PLXNC1 & $0.999(0.8576-1.164)$ & 0.0000 & 0.9896 \\
\hline PLXND1 & $0.9333(0.7795-1.118)$ & 0.5600 & 0.4530 \\
\hline$X C R 1$ & $0.9281(0.8686-0.9916)$ & 4.8800 & 0.0271 \\
\hline$A D M$ & $0.9923(0.8511-1.157)$ & 0.0100 & 0.9218 \\
\hline ADM2 & $0.9231(0.8272-1.03)$ & 2.0500 & 0.1526 \\
\hline AGRP & $1.09(1.023-1.162)$ & 7.0600 & 0.0079 \\
\hline$A M H$ & $1.217(1.123-1.319)$ & 22.8000 & 0.0000 \\
\hline ANGPTL7 & $1.022(0.9868-1.058)$ & 1.4700 & 0.2249 \\
\hline$A P L N$ & $0.879(0.7726-1)$ & 3.8400 & 0.0502 \\
\hline$B D N F$ & $0.9225(0.8517-0.9992)$ & 3.9200 & 0.0478 \\
\hline BMP1 & $1.725(1.432-2.078)$ & 32.8800 & 0.0000 \\
\hline BMP3 & $0.9922(0.9338-1.054)$ & 0.0600 & 0.8013 \\
\hline BMP5 & $0.9738(0.9435-1.005)$ & 2.7100 & 0.1000 \\
\hline BMP6 & $0.8032(0.7107-0.9078)$ & 12.3100 & 0.0004 \\
\hline BMP7 & $1.055(1.009-1.103)$ & 5.6300 & 0.0177 \\
\hline BTC & $0.9373(0.8399-1.046)$ & 1.3400 & 0.2475 \\
\hline CALCA & $0.9827(0.9524-1.014)$ & 1.2000 & 0.2741 \\
\hline$C D 70$ & $1.034(0.9736-1.099)$ & 1.1900 & 0.2746 \\
\hline CGA & $1.046(1.014-1.079)$ & 8.2300 & 0.0041 \\
\hline CGB7 & $1.094(1.02-1.173)$ & 6.3900 & 0.0115 \\
\hline CHGA & $1.116(1.06-1.174)$ & 17.5700 & 0.0000 \\
\hline$C H G B$ & $1.054(0.9852-1.127)$ & 2.3300 & 0.1273 \\
\hline СМтМЗ & $1.528(1.28-1.825)$ & 22.0200 & 0.0000 \\
\hline CMTM4 & $0.765(0.6403-0.9141)$ & 8.7000 & 0.0032 \\
\hline EB/3 & $1.26(1.089-1.458)$ & 9.6600 & 0.0019 \\
\hline$E G F$ & $0.9896(0.922-1.062)$ & 0.0800 & 0.7726 \\
\hline EPGN & $1.036(0.9994-1.075)$ & 3.7100 & 0.0541 \\
\hline$E P O$ & $1.04(1.006-1.075)$ & 5.2100 & 0.0224 \\
\hline
\end{tabular}

Table S5 (continued) 
Table S5 (continued)

\begin{tabular}{|c|c|c|c|}
\hline Gene & HR (95\% Cl) & wald.test & $P$ value \\
\hline ESM1 & $0.8378(0.7597-0.924)$ & 12.5400 & 0.0004 \\
\hline FAM3B & $1.028(0.9625-1.097)$ & 0.6700 & 0.4147 \\
\hline FGF1 & $0.836(0.7459-0.9369)$ & 9.4900 & 0.0021 \\
\hline FGF20 & $0.9713(0.9247-1.02)$ & 1.3500 & 0.2445 \\
\hline FGF7 & $1.056(0.9968-1.12)$ & 3.4300 & 0.0641 \\
\hline FGF9 & $0.9887(0.9531-1.026)$ & 0.3700 & 0.5451 \\
\hline GDF6 & $0.861(0.8067-0.919)$ & 20.2900 & 0.0000 \\
\hline GDF7 & $0.8155(0.7323-0.9082)$ & 13.7900 & 0.0002 \\
\hline GDNF & $1.001(0.9552-1.048)$ & 0.0000 & 0.9772 \\
\hline GMFG & $1.078(0.8791-1.323)$ & 0.5200 & 0.4689 \\
\hline GNRH1 & $1.377(1.228-1.545)$ & 29.7800 & 0.0000 \\
\hline GREM1 & $1.103(1.045-1.164)$ & 12.5900 & 0.0004 \\
\hline GREM2 & $1.092(1.043-1.143)$ & 14.1800 & 0.0002 \\
\hline IGF2 & $1.012(0.9508-1.078)$ & 0.1500 & 0.7003 \\
\hline IL11 & $1.114(1.046-1.187)$ & 11.4000 & 0.0007 \\
\hline IL16 & 1.002 (0.8434-1.191) & 0.0000 & 0.9806 \\
\hline IL19 & $1.023(0.9869-1.061)$ & 1.5600 & 0.2121 \\
\hline IL24 & $1.047(0.8792-1.248)$ & 0.2700 & 0.6041 \\
\hline IL32 & $1.111(0.9661-1.277)$ & 2.1800 & 0.1399 \\
\hline INHBB & $0.9928(0.8858-1.113)$ & 0.0200 & 0.9011 \\
\hline INHBE & $1.201(1.122-1.286)$ & 27.6300 & 0.0000 \\
\hline JAG2 & $0.825(0.7039-0.967)$ & 5.6400 & 0.0176 \\
\hline KITLG & $0.7393(0.6415-0.852)$ & 17.4000 & 0.0000 \\
\hline$K L$ & $0.7686(0.7125-0.8291)$ & 46.3800 & 0.0000 \\
\hline LEFTY2 & $0.9685(0.929-1.01)$ & 2.2700 & 0.1318 \\
\hline NGF & $1.095(0.9721-1.233)$ & 2.2300 & 0.1355 \\
\hline NMB & $1.117(0.9988-1.249)$ & 3.7600 & 0.0526 \\
\hline NODAL & $1.053(0.9628-1.153)$ & 1.2900 & 0.2566 \\
\hline NPPA & $1.053(0.9937-1.116)$ & 3.0400 & 0.0810 \\
\hline NRG3 & $0.8713(0.7647-0.9928)$ & 4.2800 & 0.0386 \\
\hline OGN & $0.9907(0.9436-1.04)$ & 0.1400 & 0.7069 \\
\hline OSM & $1.259(1.14-1.39)$ & 20.7800 & 0.0000 \\
\hline PDGFD & $0.6796(0.6102-0.7569)$ & 49.3700 & 0.0000 \\
\hline PGF & $1.108(1.022-1.202)$ & 6.1500 & 0.0131 \\
\hline $\mathrm{PMCH}$ & $1.047(1.006-1.089)$ & 5.1800 & 0.0229 \\
\hline PTHLH & $1.077(1.018-1.139)$ & 6.7500 & 0.0094 \\
\hline REG1A & $0.9924(0.9559-1.03)$ & 0.1600 & 0.6922 \\
\hline RETN & $1.052(0.9894-1.118)$ & 2.6100 & 0.1060 \\
\hline SCG2 & $1.094(1.019-1.175)$ & 6.0900 & 0.0136 \\
\hline STC2 & $1.024(0.9065-1.156)$ & 0.1400 & 0.7065 \\
\hline TAC1 & $0.9849(0.9565-1.014)$ & 1.0300 & 0.3090 \\
\hline TDGF1 & $1.008(0.9616-1.057)$ & 0.1100 & 0.7418 \\
\hline TNFSF13B & $1.292(1.138-1.466)$ & 15.6700 & 0.0001 \\
\hline TNFSF14 & $1.294(1.185-1.413)$ & 32.9000 & 0.0000 \\
\hline TNFSF8 & $0.9021(0.7918-1.028)$ & 2.3900 & 0.1 \\
\hline TNFSF9 & 1.109 (0.9986-1.232) & 3.7400 & 0.0532 \\
\hline TSLP & $1.117(1.015-1.23)$ & 5.0900 & 0.0240 \\
\hline UCN & $1.502(1.325-1.703)$ & 40.4400 & 0.0000 \\
\hline UTS2 & 1.047 (0.9885-1.109) & 2.4600 & 0.1171 \\
\hline VIP & 1.024 (0.9599-1.092) & 0.5100 & 0.4730 \\
\hline ACVR1C & $1.085(1.005-1.171)$ & 4.3600 & 0.0368 \\
\hline $\begin{array}{l}\text { ADCY- } \\
\text { AP1R1 }\end{array}$ & $1.004(0.9345-1.079)$ & 0.0100 & 0.9117 \\
\hline$A D R B 1$ & 1.054 (0.9778-1.136) & 1.8900 & 0.1693 \\
\hline ANGPTL1 & $0.9619(0.8979-1.031)$ & 1.2200 & 0.2700 \\
\hline ANGPTL3 & $0.8716(0.8205-0.926)$ & 19.8300 & 0.0000 \\
\hline ANGPTL4 & $0.9857(0.9072-1.071)$ & 0.1200 & 0.7342 \\
\hline APLNR & $0.7734(0.7022-0.8517)$ & 27.2300 & 0.0000 \\
\hline AVPR1B & $0.9374(0.9036-0.9726)$ & 11.8300 & 0.0006 \\
\hline AVPR2 & $0.9477(0.8718-1.03)$ & 1.5900 & 0.2080 \\
\hline BMPR1B & 1.045 (0.9961-1.096) & 3.2400 & 0.0721 \\
\hline C3AR1 & $0.9389(0.814-1.083)$ & 0.7500 & 0.3871 \\
\hline CNTFR & $1.013(0.9675-1.06)$ & 0.2900 & 0.5885 \\
\hline
\end{tabular}

Table S5 (continued)
Table S5 (continued)

\begin{tabular}{|c|c|c|c|}
\hline Gene & $\mathrm{HR}(95 \% \mathrm{Cl})$ & wald.test & $P$ value \\
\hline CRLF2 & $1.053(0.9409-1.178)$ & 0.8000 & 0.3705 \\
\hline CSF1R & $1.095(0.937-1.279)$ & 1.3000 & 0.2544 \\
\hline CSF2RA & $1.099(0.8103-1.491)$ & 0.3700 & 0.5433 \\
\hline CSF3R & $1.282(1.111-1.48)$ & 11.5200 & 0.0007 \\
\hline ESRRB & $1.013(0.9272-1.108)$ & 0.0900 & 0.7685 \\
\hline ESRRG & $0.832(0.7781-0.8897)$ & 28.9000 & 0.0000 \\
\hline FLT1 & $0.7624(0.687-0.8461)$ & 26.0700 & 0.0000 \\
\hline GCGR & $1.027(0.9957-1.058)$ & 2.8300 & 0.0923 \\
\hline HTR3B & $0.9995(0.9623-1.038)$ & 0.0000 & 0.9794 \\
\hline HTR3D & $1.036(0.9991-1.075)$ & 3.6500 & 0.0562 \\
\hline IL10RA & $1.183(1.023-1.367)$ & 5.1500 & 0.0233 \\
\hline IL12RB1 & $1.139(0.9847-1.318)$ & 3.0700 & 0.0797 \\
\hline IL17RE & $1.003(0.8672-1.161)$ & 0.0000 & 0.9645 \\
\hline IL18RAP & $1.1(0.9673-1.252)$ & 2.1200 & 0.1457 \\
\hline IL1RL1 & $0.9127(0.8575-0.9715)$ & 8.2300 & 0.0041 \\
\hline IL2ORA & $1.099(1.05-1.149)$ & 16.6600 & 0.0000 \\
\hline IL2ORB & $1.174(1.116-1.234)$ & 39.0600 & 0.0000 \\
\hline IL21R & $1.228(1.078-1.397)$ & 9.6200 & 0.0019 \\
\hline IL2RA & $1.2(1.088-1.324)$ & 13.1900 & 0.0003 \\
\hline IL2RB & $1.16(1.01-1.331)$ & 4.4300 & 0.0354 \\
\hline IL2RG & $1.172(1.037-1.324)$ & 6.4800 & 0.0109 \\
\hline$I L 4 R$ & $1.627(1.215-2.179)$ & 10.6600 & 0.0011 \\
\hline IL5RA & $1.039(0.9607-1.125)$ & 0.9300 & 0.3357 \\
\hline$I L 9 R$ & $1.112(0.9341-1.324)$ & 1.4300 & 0.2325 \\
\hline LGR5 & $1.011(0.9658-1.057)$ & 0.2100 & 0.6502 \\
\hline MCHR1 & $1.042(0.9938-1.092)$ & 2.8900 & 0.0892 \\
\hline MTNR1A & $1.005(0.9753-1.036)$ & 0.1100 & 0.7435 \\
\hline NGFR & $0.873(0.7869-0.9686)$ & 6.5600 & 0.0104 \\
\hline NROB2 & $0.995(0.9687-1.022)$ & 0.1300 & 0.7135 \\
\hline$N R 1 / 3$ & $0.9488(0.7917-1.137)$ & 0.3200 & 0.5695 \\
\hline NR2E1 & $1.027(0.9912-1.065)$ & 2.1900 & 0.1388 \\
\hline NR3C2 & $0.684(0.6156-0.7599)$ & 49.9500 & 0.0000 \\
\hline NRP2 & $1.027(0.8705-1.211)$ & 0.1000 & 0.7533 \\
\hline OPRD1 & $1.283(1.157-1.422)$ & 22.2900 & 0.0000 \\
\hline OSMR & $1.204(1.007-1.44)$ & 4.1700 & 0.0412 \\
\hline$P R L R$ & $0.9223(0.8392-1.014)$ & 2.8200 & 0.0930 \\
\hline PTGER1 & $1.113(1.066-1.161)$ & 23.6800 & 0.0000 \\
\hline PTGER3 & $0.883(0.8272-0.9426)$ & 13.9500 & 0.0002 \\
\hline PTGFR & $1.033(0.9575-1.115)$ & 0.7100 & 0.4005 \\
\hline PTH1R & $0.8624(0.7901-0.9412)$ & 11.0100 & 0.0009 \\
\hline$R O R B$ & $1.102(1.038-1.171)$ & 10.0700 & 0.0015 \\
\hline SORT1 & $0.7218(0.5917-0.8804)$ & 10.3500 & 0.0013 \\
\hline SSTR1 & $0.8821(0.8332-0.9339)$ & 18.5900 & 0.0000 \\
\hline SSTR5 & $1.009(0.9786-1.04)$ & 0.3200 & 0.5718 \\
\hline TACR1 & $0.8905(0.8405-0.9435)$ & 15.4500 & 0.0001 \\
\hline TEK & $0.661(0.5963-0.7327)$ & 62.0800 & 0.0000 \\
\hline TGFBR3 & $0.6589(0.5533-0.7845)$ & 21.9500 & 0.0000 \\
\hline THRB & $0.7559(0.6809-0.8391)$ & 27.5800 & 0.0000 \\
\hline TNFRSF14 & $1.096(0.9182-1.308)$ & 1.0300 & 0.3099 \\
\hline TNFRSF18 & $1.343(1.201-1.502)$ & 26.6000 & 0.0000 \\
\hline TNFRSF25 & $1.291(1.146-1.455)$ & 17.5600 & 0.0000 \\
\hline TNFRSF4 & $1.145(0.9977-1.315)$ & 3.7100 & 0.0539 \\
\hline TNFRSF9 & $1.1(1.019-1.188)$ & 5.9300 & 0.0149 \\
\hline TSHR & $1.012(0.9206-1.113)$ & 0.0600 & 0.8014 \\
\hline TUBB3 & $1.253(1.161-1.352)$ & 33.4700 & 0.0000 \\
\hline$I T G A L$ & $1.099(0.9618-1.256)$ & 1.9300 & 0.1651 \\
\hline ITGB2 & $1.076(0.9246-1.251)$ & 0.8900 & 0.3446 \\
\hline TYROBP & $1.17(1.004-1.364)$ & 4.0300 & 0.0446 \\
\hline LCK & $1.071(0.9487-1.21)$ & 1.2400 & 0.2664 \\
\hline FCGR3A & $1.169(1.024-1.335)$ & 5.3500 & 0.0208 \\
\hline NCR1 & $1.004(0.9128-1.105)$ & 0.0100 & 0.9298 \\
\hline NCR3 & $1.03(0.8956-1.185)$ & 0.1700 & 0.6760 \\
\hline CD247 & $1.082(0.9421-1.243)$ & 1.2500 & 0.2639 \\
\hline
\end{tabular}

Table S5 (continued) 
Table S5 (continued)

\begin{tabular}{lccc}
\hline Gene & HR $(95 \% \mathrm{Cl})$ & wald.test & P value \\
\hline ZAP70 & $1.263(1.114-1.432)$ & 13.2500 & 0.0003 \\
LCP2 & $1.136(0.9377-1.377)$ & 1.7000 & 0.1922 \\
LAT & $1.219(1.113-1.334)$ & 18.3100 & 0.0000 \\
SH3BP2 & $0.9829(0.8002-1.207)$ & 0.0300 & 0.8697 \\
SHC3 & $1.21(1.068-1.371)$ & 8.9100 & 0.0028 \\
HCST & $1.333(1.176-1.511)$ & 20.2800 & 0.0000 \\
CD48 & $1.02(0.8893-1.169)$ & 0.0800 & 0.7791 \\
CD244 & $1.092(0.9463-1.26)$ & 1.4500 & 0.2288 \\
SH2D1A & $1.068(0.9617-1.186)$ & 1.5100 & 0.2192 \\
GZMB & $1.191(1.046-1.355)$ & 6.9900 & 0.0082 \\
PRF1 & $1.01(0.8847-1.154)$ & 0.0200 & 0.8780 \\
CD3D & $1.076(0.9746-1.189)$ & 2.1100 & 0.1465 \\
CD3E & $1.087(0.9787-1.208)$ & 2.4300 & 0.1190 \\
CD3G & $1.007(0.9079-1.118)$ & 0.0200 & 0.8911 \\
PTPRC & $0.9737(0.8521-1.113)$ & 0.1500 & 0.6953 \\
ITK & $1.059(0.9375-1.197)$ & 0.8500 & 0.3552 \\
GRAP2 & $1.012(0.8767-1.169)$ & 0.0300 & 0.8663 \\
PAK6 & $1.052(1.009-1.097)$ & 5.6000 & 0.0180 \\
PAK7 & $1.039(1.004-1.074)$ & 4.9000 & 0.0269 \\
CD28 & $1.089(0.9705-1.221)$ & 2.1000 & 0.1474 \\
ICOS & $1.059(0.9668-1.161)$ & 1.5300 & 0.2167 \\
CTLA4 & $1.175(1.073-1.286)$ & 12.2000 & 0.0005 \\
CBLC & $1.01(0.9406-1.085)$ & 0.0800 & 0.7763 \\
PDK1 & $0.8721(0.7111-1.07)$ & 1.7300 & 0.1887 \\
PRKCQ & $0.878(0.7667-1.006)$ & 3.5400 & 0.0601 \\
\hline & & & \\
\hline
\end{tabular}


Table S6 Information for 8 candidate IRGs identified by the multivariate Cox regression analysis

\begin{tabular}{lcccc}
\hline Gene & $\mathrm{HR}$ & $95 \% \mathrm{Cl}$ & coef & P value \\
\hline CRABP2 & 1.07676 & $1.0011-1.1582$ & 0.07396 & 0.04669 \\
LTB4R & 1.17957 & $1.0013-1.3895$ & 0.16515 & 0.04817 \\
PLAUR & 1.15893 & $0.9737-1.3794$ & 0.1475 & 0.09689 \\
PLXNB3 & 1.07077 & $0.9532-1.2028$ & 0.06838 & 0.24901 \\
KL & 1.01536 & $0.9014-1.1437$ & 0.01525 & 0.80181 \\
IL2ORB & 1.05249 & $0.9898-1.1191$ & 0.05115 & 0.10246 \\
PTGER1 & 1.05377 & $1.0075-1.1022$ & 0.05238 & 0.02223 \\
TEK & 0.81594 & $0.7110-0.9363$ & -0.20342 & 0.00377 \\
\hline
\end{tabular}

Table S7 immune cell infiltration in two groups

\begin{tabular}{|c|c|c|}
\hline Immune cell type & Low-risk group & High-risk group \\
\hline B cell naive_CIBERSORT & 0.0157494 & 0.0101317 \\
\hline B cell memory_CIBERSORT & 0.00053044 & 0.002702 \\
\hline B cell plasma_CIBERSORT & 0.05507898 & 0.0458001 \\
\hline T cell CD8+_CIBERSORT & 0.15163708 & 0.1820687 \\
\hline T cell CD4+ naive_CIBERSORT & 0 & 3.689E-05 \\
\hline T cell CD4+ memory resting_CIBERSORT & 0.14163721 & 0.1243761 \\
\hline T cell CD4+ memory activated_CIBERSORT & 0.00030018 & 0.0021332 \\
\hline T cell follicular helper_CIBERSORT & 0.02126128 & 0.0350954 \\
\hline T cell regulatory (Tregs)_CIBERSORT & 0.00902234 & 0.0205732 \\
\hline T cell gamma delta_CIBERSORT & 0.0216898 & 0.0204485 \\
\hline NK cell resting_CIBERSORT & 0.00976917 & 0.0090843 \\
\hline NK cell activated_CIBERSORT & 0.04972058 & 0.0598868 \\
\hline Monocyte_CIBERSORT & 0.05737104 & 0.0467553 \\
\hline Macrophage MO_CIBERSORT & 0.00726102 & 0.0274406 \\
\hline Macrophage M1_CIBERSORT & 0.0631331 & 0.0547069 \\
\hline Macrophage M2_CIBERSORT & 0.34385585 & 0.3146842 \\
\hline Myeloid dendritic cell resting_CIBERSORT & 0.00323255 & 0.0012643 \\
\hline Myeloid dendritic cell activated_CIBERSORT & 0.00204996 & 0.0016187 \\
\hline Mast cell activated_CIBERSORT & 0.02880841 & 0.0189666 \\
\hline Mast cell resting_CIBERSORT & 0.01334313 & 0.0156609 \\
\hline Eosinophil_CIBERSORT & 0.00025604 & 0.0001598 \\
\hline Neutrophil_CIBERSORT & 0.00429245 & 0.0064058 \\
\hline
\end{tabular}


Table S8 Clinical information of patients

\begin{tabular}{|c|c|}
\hline Variable & No. of patients \\
\hline \multicolumn{2}{|l|}{ Gender } \\
\hline Male & 23 \\
\hline Female & 12 \\
\hline \multicolumn{2}{|l|}{ Age } \\
\hline$\geq 60$ & 9 \\
\hline$<60$ & 26 \\
\hline \multicolumn{2}{|c|}{ Histological grade } \\
\hline G1 & 7 \\
\hline G2 & 23 \\
\hline G3 & 2 \\
\hline G4 & 3 \\
\hline \multicolumn{2}{|l|}{ Stage } \\
\hline I & 18 \\
\hline II & 5 \\
\hline III & 6 \\
\hline IV & 6 \\
\hline \multicolumn{2}{|l|}{ T stage } \\
\hline I & 21 \\
\hline II & 7 \\
\hline III & 7 \\
\hline IV & 0 \\
\hline \multicolumn{2}{|l|}{$\mathrm{N}$ stage } \\
\hline No & 33 \\
\hline $\mathrm{N} 1$ & 2 \\
\hline \multicolumn{2}{|l|}{ M stage } \\
\hline Mo & 31 \\
\hline M1 & 4 \\
\hline
\end{tabular}

Table S9 Variable corresponding point

\begin{tabular}{|c|c|}
\hline Variable & Point \\
\hline \multicolumn{2}{|l|}{ Age } \\
\hline$\geq 60$ & 7 \\
\hline$<60$ & 0 \\
\hline \multicolumn{2}{|l|}{ Gender } \\
\hline Male & 0 \\
\hline Female & 1 \\
\hline \multicolumn{2}{|l|}{ T stage } \\
\hline 1 & 1 \\
\hline II & 0 \\
\hline III & 5 \\
\hline IV & 6 \\
\hline \multicolumn{2}{|l|}{ N stage } \\
\hline NO & 3 \\
\hline N1 & 5 \\
\hline $\mathrm{Nx}$ & 0 \\
\hline \multicolumn{2}{|l|}{ M stage } \\
\hline MO & 20 \\
\hline M1 & 36 \\
\hline $\mathrm{Mx}$ & 0 \\
\hline \multicolumn{2}{|c|}{ Histological grade } \\
\hline G1 & 0 \\
\hline G2 & 94 \\
\hline G3 & 97 \\
\hline G4 & 100 \\
\hline \multicolumn{2}{|l|}{ Necrosis } \\
\hline Yes & 9 \\
\hline No & 0 \\
\hline \multicolumn{2}{|c|}{ Risk_score } \\
\hline-1 & 0 \\
\hline-0.5 & 9 \\
\hline 0 & 18 \\
\hline 0.5 & 26 \\
\hline 1 & 35 \\
\hline 1.5 & 44 \\
\hline 2 & 53 \\
\hline 2.5 & 62 \\
\hline 3 & 70 \\
\hline
\end{tabular}

